\title{
Open Automated Demand Response Dynamic Pricing Technologies and Demonstration
}

\author{
Girish Ghatikar, Johanna L. Mathieu, Mary Ann Piette, Lawrence Berkeley National \\ Laboratory \\ Ed Koch, Dan Hennage, Akuacom
}

August 2010 


\section{Disclaimer}

This document was prepared as an account of work sponsored by the United States Government. While this document is believed to contain correct information, neither the United States Government nor any agency thereof, nor The Regents of the University of California, nor any of their employees, makes any warranty, express or implied, or assumes any legal responsibility for the accuracy, completeness, or usefulness of any information, apparatus, product, or process disclosed, or represents that its use would not infringe privately owned rights. Reference herein to any specific commercial product, process, or service by its trade name, trademark, manufacturer, or otherwise, does not necessarily constitute or imply its endorsement, recommendation, or favoring by the United States Government or any agency thereof, or The Regents of the University of California. The views and opinions of authors expressed herein do not necessarily state or reflect those of the United States Government or any agency thereof or The Regents of the University of California. 


\section{Acknowledgements}

The work described in this report was coordinated by the Demand Response Research Center and funded by the California Energy Commission (Energy Commission), Public Interest Energy Research (PIER) Program, under Work for Others Contract No. 500-03-026 and by the U.S. Department of Energy under Contract No. DE-AC02-05CH11231. 


\begin{abstract}
This study examines the use of the OpenADR communications specification version 1.0 (OpenADR v1.0), related data models, technologies, and strategies to send dynamic prices such as real-time prices and peak prices and time-of-use rates to commercial and industrial electricity customers. OpenADR v1.0 is a Web services-based flexible, open information model that has been used in California utilities' commercialized automated demand response programs since 2007. The OpenADR v1.0 data model can be used to send dynamic prices and time-of-use rates. This study's project team developed an interface that allows the utility or independent system operator to manually enter "day-ahead" or "day-of" dynamic prices. The team also developed a method for extracting dynamic prices from real-time Internet feeds. Dynamic prices can be delivered in the form of actual prices (in dollars) or mapped into "operation modes." with both formats acting as inputs to building control systems. The report presents several different methods for mapping actual prices, some of which were implemented in demonstration projects. The study results show that OpenADR allows interoperability with existing and future systems and technologies, and that it can be used in related dynamic pricing activities within the Smart Grid.
\end{abstract}

Keywords: Commercial and industrial, peak demand, demand response, dynamic pricing, realtime pricing, control and information technology, OpenADR, Open Automated Demand Response, Smart Grid

Please cite this report as follows:

Ghatikar, G., J. L. Mathieu, M. A. Piette (Lawrence Berkeley National Laboratory), E. Koch, and D. Hennage (Akuacom, Inc.). 2010. Open Automated Demand Response Dynamic Pricing Technologies and Demonstration. California Energy Commission. CEC-500-XXXX-XXX. 


\section{Table of Contents}

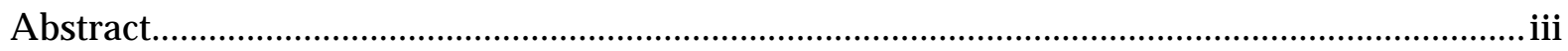

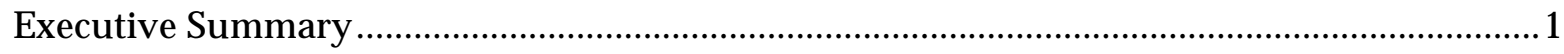

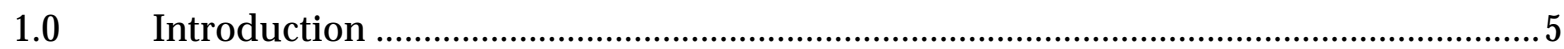

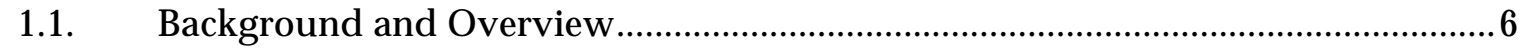

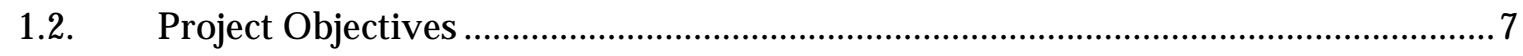

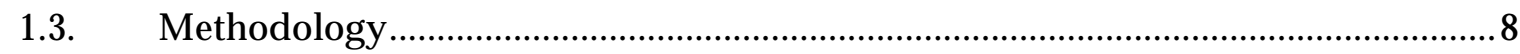

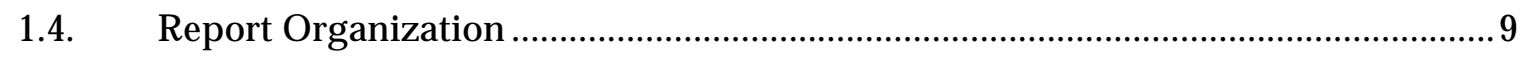

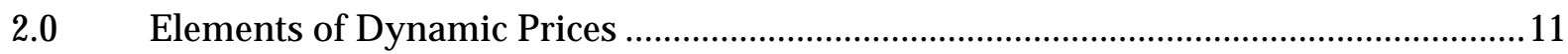

2.1. Existing Dynamic Pricing Programs .............................................................. 11

2.2. Wholesale Electricity Market Information Systems ..............................................12

2.3. OpenADR Dynamic Pricing Technology Architecture ..........................................13

2.3.1. OpenADR Version 1.0 DR Program Interfaces ................................................13

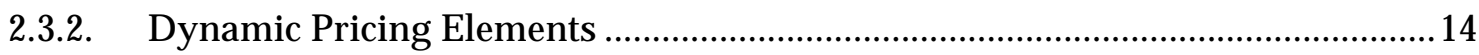

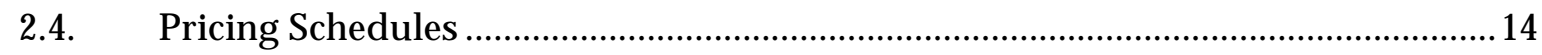

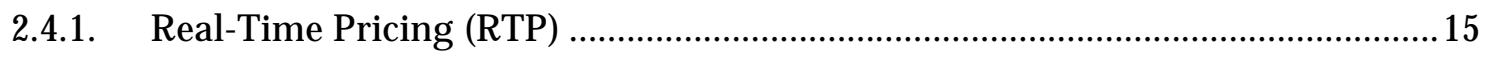

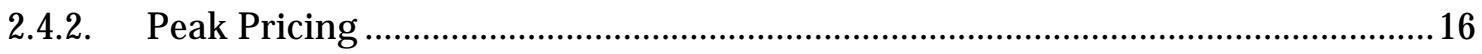

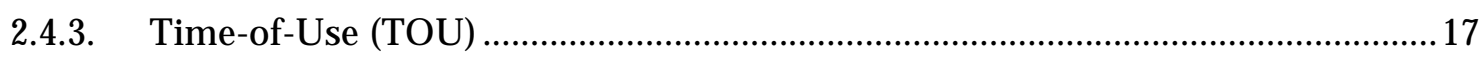

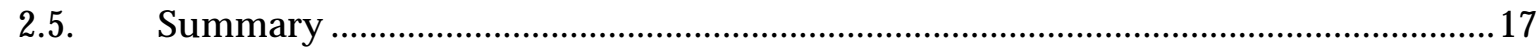

3.0 Dynamic Pricing Development for Demonstration ...............................................18

3.1. Dynamic Pricing Interfaces and Technology Architecture ...................................18

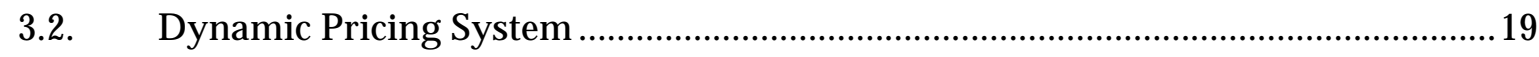

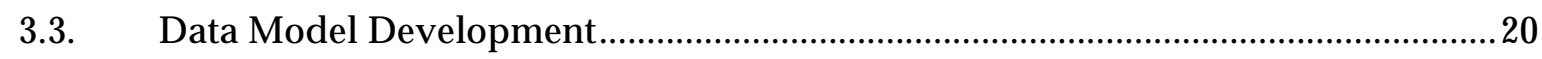

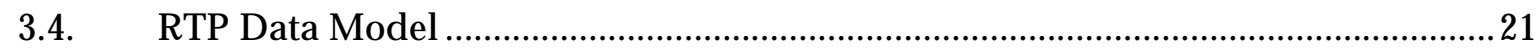

3.5. Peak Pricing and TOU Pricing Data Models...........................................................23

3.5.1. Using the RTP Data Model for Peak Prices .........................................................23

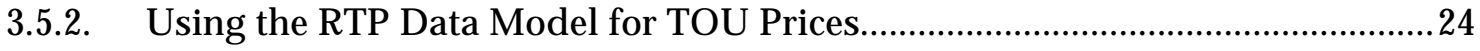

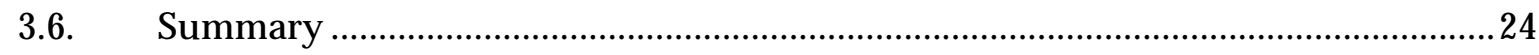

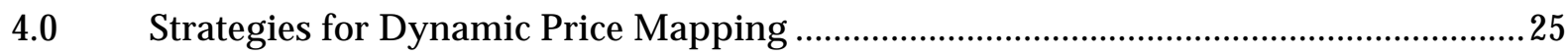

4.1. Scenario 1: Absolute Price Mapping ......................................................................25

4.1.1. The California Energy Commission and Sacramento Municipal Utility District

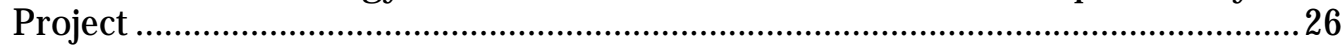

4.1.2. Electric Power Research Institute Project .......................................................26

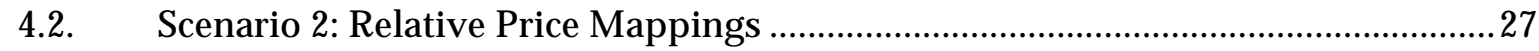

4.2.1. Electricity Market Price Volatility …...............................................................28

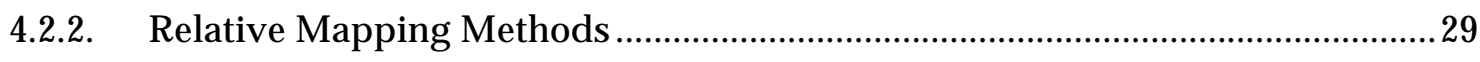

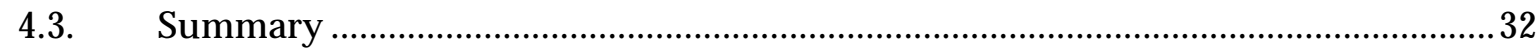

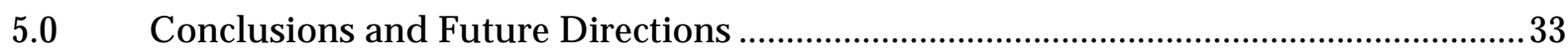

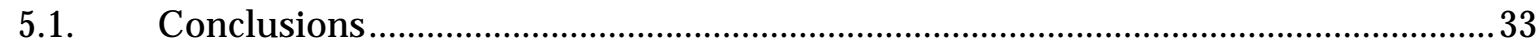




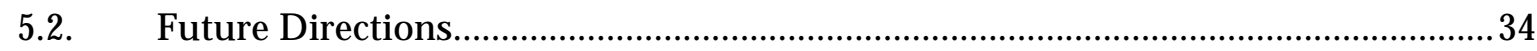

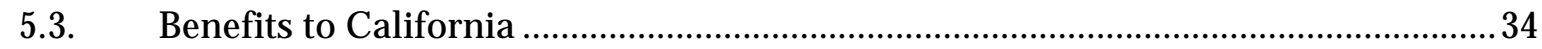

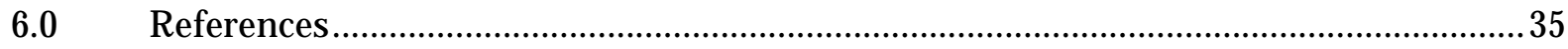

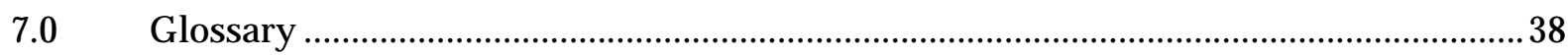

Appendix A: SCE RTP Tariff Structure

Appendix B: Screenshots of OpenADR Interfaces

Appendix C: CAISO Wholesale Prices and OASIS Data Models

Appendix D: PG\&E PDP Rate Schedules and Rate Sheets

\section{List of Figures}

Figure 1. OpenADR Version 1.0 Utility or ISO, and Customer Interfaces to DRAS ......................13

Figure 2. Technology Architecture of OpenADR Utility or ISO Interfaces for Dynamic Pricing

Figure 3. Structure OpenADR Dynamic Pricing Technology Architecture and Client Interfaces..

Figure 4. Hourly Price Schedule Mapping Developed for the SMUD Project...............................26

Figure 5. Average Daily Real-Time Prices and Price Duration Curves for a Low Price Year (Year

1) and a High Price Year (Year 2) ..........................................................................................28

Figure 6. CAISO Wholesale DA Hourly LMP for a Node …........................................................29 
Figure 7. Relative Mapping with Number of Hours per Operation Mode

Figure 8. Relative Mapping Using Average (left) and High (right) Electricity Price References..32

\section{List of Tables}

Table 1. Source of Prices Used for Each Pricing Schedule .............................................................14

Table 2. CAISO Wholesale RTP Programs via OASIS (Adapted from CAISO 2010) ....................16

Table 3. Participants Mapping Criteria for Price Multiplier to Price …..........................................27 


\section{Executive Summary}

\section{Introduction}

In December of 2008, the California Energy Commission (Energy Commission) proposed a portfolio of load management standards directed at encouraging a ubiquitous electric demand response network. Included in the proposed standards are requirements directing all California investor-owned utilities and municipal utilities to "...establish a standard method for transmitting current rate and reliability information to customers," and to "...develop programs supporting customer adoption of enabling technologies...capable of facilitating customer load reductions in response to dynamic electricity prices using the Open Automated Demand Response (OpenADR)."

The Open Automated Demand Response Communications Specification is a Web servicesbased flexible, open data model that has been used in California utilities' commercialized Automated Demand Response programs and a California Independent System Operator's ancillary-services pilot program for participating loads. OpenADR can be used to send both price- and reliability-based demand response information to building control systems (such as energy management control systems) and end-use control systems (such as lighting controls) in both large commercial and industrial facilities.

OpenADR is part of the National Institute of Standards and Technology's initial set of sixteen standards for the U.S. Smart Grid interoperability standards framework. It is in the process of being standardized within standards development organizations and user groups. Long-term plans for OpenADR include making it an international standard with organizations such as the International Electrotechnical Commission.

This report describes how the OpenADR data model(s) can be used to represent a variety of dynamic electricity price structures. In this study, dynamic pricing is defined as electricity pricing in which the consumer does not know their electricity prices more than a day in advance. Examples of dynamic pricing include:

1. Real-Time Pricing: Electricity prices vary throughout the day as a function of environmental conditions (such as outdoor air temperature), and/or electricity supply and demand conditions. Real-time pricing tariffs can be set day-ahead (that is, tariffs take effect next day) or day-of (that is, tariffs take effect same day). An example of real-time pricing is Southern California Edison's real-time pricing tariff.

2. Peak Pricing: In peak pricing tariffs, electricity prices on peak days are different than electricity prices on non-peak days. Prices are generally preset; however, the consumer does not know if a certain day will be a peak day or a non-peak day until day-ahead or day-of. Peak days are called as a function of environmental conditions (such as outdoor air temperature) and/or electricity supply and demand conditions. Examples include Pacific Gas and Electric's Peak Day Pricing program and Southern California Edison's Critical Peak Pricing program.

Time-of-use pricing is defined here as electricity pricing in which the consumer knows his or her electricity prices more than a day in advance, though the price varies throughout the day. 


\section{Purpose and Project Objectives}

This study evaluated dynamic and TOU pricing structures and used the existing OpenADR specification to develop and test OpenADR data models for a wider variety of dynamic pricing rates than had previously been evaluated. Researchers also investigated methods for mapping dynamic electricity prices to simpler information that can be used directly by building control and end-use systems in commercial and industrial facilities. The report references two technology demonstrations that implemented OpenADR dynamic pricing data models. The project objectives were as follows:

1. Develop an OpenADR data model to represent dynamic electricity prices such as realtime and peak prices (and/or related signals). The data model will be used to send dynamic prices to commercial and industrial facilities.

2. Evaluate if existing static electricity prices such as time-of-use prices can be represented using the same OpenADR data models as those proposed for dynamic pricing structure.

3. Evaluate methods of mapping dynamic prices to simple information (such as operational modes) including a technology demonstration of how a facility's control systems and/or end-use devices can use the information.

This project was an evaluation of OpenADR data models for dynamic pricing, and its scope was not intended to address the following issues:

- How reliability and/or emergency events can be represented using OpenADR data models and signals.

- How dynamic pricing information can be used by a diverse set of facility control systems or enable customer engagement by displaying prices.

- How building control and information systems such as energy management control systems and energy information systems could be programmed to respond to and display dynamic pricing signals.

- How dynamic pricing signals are used to automate a facility's demand response strategies for load shedding or shifting, and offer solutions to any challenges resulting from participation in dynamic pricing demand response programs.

\section{Conclusions and Key Findings}

This study has found that the OpenADR data models support most day-ahead and day-of dynamic pricing structures for California utility retail electricity rates and independent system operator programs. The results from this technology demonstration are estimated to affect national retail dynamic pricing communication and policy. Related key findings are as follows:

- OpenADR data models can be used to send real-time prices.

- OpenADR real-time pricing data models can also be used to support peak pricing and time-of-use rates.

- OpenADR customers can respond to dynamic prices by either using the actual prices or map these prices into "operation modes," which can be used as inputs to control systems. 
- Open ADR allows interoperability with existing and future systems and technologies.

- The results from this study could be used for wider application within Smart Grids.

\section{Key Challenges}

While there has been significant progress in demonstrating the application of OpenADR to a variety of dynamic pricing structures, there are a number of remaining key challenges:

- The OpenADR data model has placeholder for real-time feedback and energy use, which has had limited use in a few demonstrations. This information would be useful for facilities participating in programs such as peak-time rebate programs or those programs with demand charges.

- Wholesale energy market prices are volatile, and further research is needed on customer strategies to cope with the volatility of retail energy prices.

- Utilities use a variety of methods to set real-time prices (such as weather-dependent, market-dependent, and other methods). More research is needed to determine the best ways for utilities to set real-time prices and how OpenADR can send them.

\section{Future Directions}

OpenADR has been used in a variety of programs in California, the Northwest, and Canada, and is in development for a number of demand response programs around the United States and abroad. OpenADR could benefit from the development and execution of future projects to demonstrate a broader set of capabilities. Future activities could include the following:

- Field demonstration of real-time pricing data models and automated control response strategies in a variety of commercial and industrial facilities.

- Assessment of existing California default dynamic pricing programs' impact on facilities' transition to Auto-DR.

- Further research on price-to-operational mode mapping strategies.

- Case studies on dynamic pricing programs in other areas (for example, Georgia Power) and their applicability to OpenADR.

\section{Benefits to California}

The transition of California's electricity markets toward dynamic pricing (for example, peak pricing) within the next few years could significantly affect electricity costs for many facilities. The price of electricity and the stress on the electric grid is high during peak days. Price response strategies enable customers to lower operational electricity costs and reduce grid stress. This results in alleviation of blackouts or brownouts and the need for peaker plants. Communicating prices can facilitate price-response strategies. OpenADR-based infrastructure can communicate dynamic pricing information (such as hourly and sub-hourly information) to facilities in real time, while offering a secure and open system, which enables facilities to reduce their electricity costs. Standardized OpenADR interfaces can be used to link wholesale and retail real-time prices. 


\subsection{Introduction}

In December of 2008, the California Energy Commission (Energy Commission) proposed a portfolio of load management standards directed at encouraging a ubiquitous electric demand response (DR) network. Included in the proposed standards are requirements directing all California investor-owned utilities and municipal utilities to "...establish a standard method for transmitting current rate and reliability information to customers," and to "...develop programs supporting customer adoption of enabling technologies...capable of facilitating customer load reductions in response to dynamic electricity prices using the Open Automated Demand Response (OpenADR) communication..." specification version 1.0 (Piette et al. 2009). The Federal Energy Regulatory Commission (FERC) recently published a report that concludes that "the largest gains in demand response can be made through dynamic pricing programs when they are offered as the default tariff, particularly when they are offered with enabling technologies" (FERC 2009).

OpenADR is a Web services-based flexible, open data model that has been used in California utilities' commercial Automated Demand Response (Auto-DR) programs (Wikler et al. 2007), California Independent System Operator's (CAISO) ancillary-services pilot programs for participating loads (Kiliccote et al. 2009), and Pacific Northwest pilot Auto-DR programs (Kiliccote et al. 2010a). OpenADR can send both price- and reliability-based DR information to building control systems, such as energy management control systems (EMCS), and end-uses, such as lighting controls, in large commercial and industrial (C\&I) facilities. Energy Information Systems (EIS) could also display pricing information to customers. Dynamic pricing information made available through EIS would enable electricity customers to better understand and manage energy consumption and costs.

OpenADR is part of the National Institute of Standards and Technology's (NIST) initial set of sixteen standards for the U.S. Smart Grid interoperability standards framework. It is identified as a specification for standardization of DR signals (NIST 2010). OpenADR is in the process of being standardized within the Organization for Advancement of Structured Information Standards, which is a standards development organization or SDO (OASIS SDO 2010a; OASIS SDO 2010b), and within the Utilities Communications Architecture, which is a user group (Open Smart Grid Users Group 2010). Long-term plans for OpenADR include making it an international standard with organizations such as the International Electrotechnical Institute. The Federal Energy Regulatory Commission explains that "standardizing demand response signaling could make it easier for facilities to respond to calls for load reductions and management, and potentially increase the amount of customer participation in demand response program products" (FERC 2010). They also believe that OpenADR could be an example of such a standard (FERC 2010).

This report details efforts to send dynamic prices to customers using existing OpenADR information models. Dynamic pricing is one way of achieving DR, defined by the U.S. Department of Energy (DOE) as "a tariff or program established to motivate changes in electric use by end-use customers in response to changes in the price of electricity over time, or to give incentive payments designed to induce lower electricity use at times of high market prices or when grid reliability is jeopardized" (DOE 2006). DR has many benefits. It can be used to reduce electricity price volatility during peak periods (Borenstein et al. 2002), and it contributes 
to system reliability (NERC 2008). Several studies have attempted to understand and quantify the benefits DR (FERC 2009; DOE 2006; Borenstein et al. 2002).

In this study, dynamic pricing is defined as electricity pricing in which the consumer does not know their electricity prices more than a day in advance. Examples include the following:

1. Real-Time Pricing (RTP): Electricity prices vary throughout the day as a function of environmental conditions (e.g., outdoor air temperature), and/or electricity supply and demand conditions. Real-Time Pricing tariffs can be set day-ahead or day-of. An example of an RTP is Southern California Edison's (SCE'S) RTP tariff (SCE 2010b).

2. Peak Pricing: In peak pricing tariffs, electricity prices on peak days are different than electricity prices on non-peak days. Prices are generally preset; however, the consumer does not know if a certain day will be a peak day or a non-peak day until day-ahead or day-of. Peak days are called as a function of environmental conditions (e.g., outdoor air temperature), and/or electricity supply and demand conditions. Examples include Pacific Gas and Electric's (PG\&E's) Peak Day Pricing (PDP) program (PG\&E 2010b) and SCE's Critical Peak Pricing (CPP) program (SCE 2010a).

Time-of-use (TOU) pricing is defined here as electricity pricing in which the consumer knows their electricity prices more than a day in advance, though the price varies throughout the day.

This study evaluated dynamic and TOU pricing structures and used the existing OpenADR specification to develop and test OpenADR data models for a wider variety of dynamic pricing rates than had previously been evaluated. Researchers investigated methods for mapping dynamic electricity prices to simpler information that can be used directly by building control and end-use systems in C\&I facilities. In addition, the report references two technology demonstrations that implemented OpenADR dynamic pricing data models (Herter et al. 2008; Herter et al, 2009; Herter et al. 2010).

\subsection{Background and Overview}

In 2007, the California Public Utilities Commission (CPUC) mandated that California investorowned utilities offer commercial Auto-DR programs based on OpenADR and related technologies developed by Lawrence Berkeley National Laboratory (LBNL) (Piette et al. 2009). Since then, OpenADR has been used in California utilities' commercialized Auto-DR programs to send CPP and Demand Bidding Program (DBP) event information to a number of large C\&I facility customers (Wikler et al. 2007). In 2008, LBNL and the Energy Commission formally released the OpenADR version 1.0 communication specification to the public. In 2010, the CPUC approved PG\&E's filing for the PDP rate structure (PG\&E 2010b) to replace the CPP program. On May 1, 2010, all C\&I facilities in the PG\&E service territory that have had an interval meter for more than 12 months and three consecutive months of a demand greater than $200 \mathrm{~kW}$ (during the last 12 months) were automatically placed on PDP rates. In addition, all C\&I customers of any size who participate in certain existing DR programs were also automatically placed on PDP rates. By November 1, 2011, all C\&I customers, including those with demands less than 200 kilowatts (kW), will automatically be placed on PDP rates (though C\&I facilities may opt out of the PDP pricing plan to TOU rates). With such a large number of customers who are now on the newly approved PDP rates, the development of OpenADR data models for 
dynamic pricing programs is critical. OpenADR is also being considered for automation with other non-dynamic pricing DR programs, such as the Capacity Bidding Program and Peak Choice for C\&I facility customers; however, these programs are not the focus of this study.

Many California commercialized DR programs (e.g., CPP, DBP) for C\&I facilities were automated starting in 2007. As a result, 303 facilities use OpenADR to participate in DR. In total, the facilities were able to provide over 55 megawatts (MW) of peak demand reduction, with a percent peak demand reduction (calculated by dividing the average actual load shed by the average peak load for each DR event) of 24\% (Kiliccote et al. 2010b).

The development of OpenADR communication data models for CPP and DBP customers included open standards-based data models for information exchange to facilitate extensibility (e.g., legacy systems and ease of participation) and backward compatibility (e.g., with existing DR strategies) of Auto-DR programs. This common information exchange was made possible by mapping smart client information to simple client information, defined as follows (Piette et al. 2009):

- Simple Client Information: The simple client information mainly consists of eventpending signal (e.g., yes/no, or simple quantification of how far in advance a notification is sent), operation modes (e.g., normal, moderate), time, and operation mode schedules.

- Smart Client Information: The smart client information consists of additional items such as event notification time, start time, end time, and other event related details (e.g., actual prices, information type) that a customer could use if needed. Smart client information was intended for facilities with sophisticated controls (e.g., Internet connectivity, logic processing) capable of using complete dynamic pricing data.

- Mapping Structure: A mapping structure, customized by the individual facility, is an algorithm that resides within the utility, the facility, or the third-party (e.g., OpenADR server, EMCS) to map the smart client information into simple client information (e.g., mapping real-time prices to "normal, moderate, or high" operation modes).

For the mapping structure, the facilities use operation mode schedules to map CPP and DBP event periods to end-use DR control strategies. This strategy enables commonalities and consistency between varied DR programs. For example, PG\&E's CPP program has two pricing periods: one in which prices are three times normal $(12-3 \mathrm{pm})$ and one in which prices are five times normal (3-6 pm). The pricing periods were mapped to load sheds with "moderate" and "high" operation modes, respectively. Similarly, in DBP, the DR program information was also used to map the load sheds to "normal, moderate, or high" operation modes for periods when the facility was able to participate (Wikler et al. 2007). Using simple client information, PG\&E's $\mathrm{CPP}$ and DBP customers were also able to participate in CAISO's Participating Load Pilot program for ancillary services (non-spinning reserve) without any modification to their strategies (Kiliccote et al. 2009).

\subsection{Project Objectives}

The project objectives were to: 
1. Develop an OpenADR data model to represent dynamic electricity prices such as realtime and peak prices (and/or related signals). The data model will be used to send dynamic prices to C\&I facilities.

2. Evaluate if existing static electricity prices such as TOU prices can be represented using the same OpenADR data models as those proposed for dynamic pricing structure.

3. Evaluate methods of mapping dynamic prices to simple information (e.g., operational modes) including a technology demonstration of how a facility's control systems and/or end-use devices can use the information.

This project was an evaluation and development of OpenADR data models for dynamic pricing and its scope was not intended to address the following issues:

- How reliability and/or emergency events can be represented using OpenADR data models and signals.

- How dynamic pricing information can be used by a diverse set of facility control systems or enable customer engagement by displaying prices.

- How building control and information systems such as EMCS and EIS could be programmed to respond to and display dynamic pricing signals.

- How dynamic pricing signals are used to automate a facility's DR strategies for load shedding or shifting, and offer solutions to any challenges resulting from participation in dynamic pricing DR programs.

\subsection{Methodology}

The primary focus of this study was to develop data models to represent dynamic electricity prices. Using the data models, the prices can be sent to C\&I facilities that have 15-minute interval meters. A previous project performed a technology demonstration of timedifferentiated prices for residential buildings with one-hour interval meters (Herter et al. 2008; Herter et al. 2009; Herter et al. 2010).

The tasks associated with the study presented here were as follows:

1. Determine the key elements of dynamic pricing structures for implementation and testing.

2. Develop and demonstrate data models to represent dynamic prices with OpenADR.

3. Develop and demonstrate an automated linkage of OpenADR with real-time Internet feeds that publish real-time electricity prices.

4. Evaluate the data models' ability to represent a range of California electricity pricing tariffs (including RTP, PDP, and TOU).

5. Develop methods for mapping dynamic prices into simpler signals (e.g., operational modes) that can be used for technology demonstrations within facilities.

This project examined a range of dynamic pricing programs in California, and one in New York. It also examined several wholesale electricity markets (California, New England, New York) to understand elements of wholesale electricity price information. Based on that information, 
researchers determined the elements required to represent dynamic prices in OpenADR data models.

We developed an OpenADR data model to allow the utility to send real-time prices to customers. Because we were unable to find any utilities that publish real-time electricity prices using real-time Internet feeds, for the purposes of technology demonstration we linked OpenADR with a real-time Internet feed developed by the California Independent Systems Operator (CAISO) for publishing real-time wholesale electricity prices. We also developed a manual interface that allows the utility or ISO to enter the prices directly.

The RTP data models developed in this study were evaluated for use with PG\&E's PDP program. For this, we studied four of PG\&E's PDP rate schedules. The rate schedules A-1 and A-6 are intended for small/medium C\&I customers (demands less than $200 \mathrm{~kW}$ ), and E-19 and E-20 are intended for large C\&I customers (demands greater than $499 \mathrm{~kW}){ }^{1}$ The data model was then evaluated for use with a TOU tariff. Finally, we examined mapping structures (mapping smart client information to simple client information, as defined above). Since some existing and new DR customers prefer simple client information, these mapping structures could extend the range of customers willing to participate in dynamic pricing programs.

\subsection{Report Organization}

The remainder of this report is organized as follows:

Section 2.0 describes the key elements of dynamic prices.

Section 0 summarizes the development and demonstration of different dynamic pricing data models using the OpenADR version 1.0 specification.

Section 4.0 describes mapping strategies to communicate simplified dynamic pricing signals to facilities.

Section 5.0 presents conclusions and future directions.

Sections 6.0 and 7.0 list references, glossary of key terminology used in this report, and followed by appendices that contain further analysis and details.

Appendix A includes tables describing SCE's RTP Tariff for large (>500kW) C\&I facilities.

Appendix B includes screen shots of DRAS used for the RTP technology demonstration.

Appendix C describes data models for CAISO real-time wholesale market prices.

Appendix D includes information on PG\&E's PDP rate schedules.

\footnotetext{
${ }^{1}$ PG\&E's PDP Charges and Credits. http://www.pge.com/mybusiness/energysavingsrebates/demandresponse/peakdaypricing/facts/char ges/
} 


\subsection{Elements of Dynamic Prices}

This section evaluates several dynamic pricing programs offered in the United States in an effort to identify elements that should be represented within OpenADR data models. The project began by examining a range of dynamic pricing tariffs throughout California, and one in New York. It also examined several wholesale electricity markets (California, New England, New York) to understand how electricity prices and related information are published. This information was then used to determine which elements of dynamic pricing tariffs should be represented in OpenADR data models.

\subsection{Existing Dynamic Pricing Programs}

This study examined a range of existing dynamic pricing tariffs offered by investor-owned utilities in California and one in New York. It focused on California because, (1) it was easiest there to access tariff information and other technical information that might be necessary for OpenADR technology integration, and (2) there are future plans to demonstrate California facilities' ability to respond to dynamic pricing. The dynamic pricing tariffs studied include the following:

1. Southern California Edison's (SCE) Real-Time Pricing (RTP) Tariff for large (>500 kW) C\&I facilities: The customers on SCE's RTP tariff are billed hourly electricity prices that vary based on the time of day, season, and the weather-specifically the previous day's high temperature as recorded in downtown Los Angeles by the National Weather Service. Daily electricity prices for each season and for various temperature intervals (i.e., $<80^{\circ} \mathrm{F}\left[27^{\circ} \mathrm{C}\right], 81^{\circ} \mathrm{F}-84^{\circ} \mathrm{F}\left[27^{\circ} \mathrm{C}-29^{\circ} \mathrm{C}\right], 85^{\circ} \mathrm{F}-90^{\circ} \mathrm{F}\left[29^{\circ} \mathrm{C}-32^{\circ} \mathrm{C}\right], 91^{\circ} \mathrm{F}-94^{\circ} \mathrm{F}$ $\left[33^{\circ} \mathrm{C}-34^{\circ} \mathrm{C}\right]$, and $>95^{\circ} \mathrm{F}\left[35^{\circ} \mathrm{C}\right]$ ) are preset and so all that is required to determine electricity use is knowledge of the season and previous day's high temperature (SCE 2010b). See Appendix A for table of SCE's weather-based RTP tariff structure.

2. Pacific Gas \& Electric Company's (PG\&E) Peak Day Pricing (PDP) Program for C\&I facilities: Peak day pricing days are triggered by high temperatures, California Independent System Operator (CAISO) emergencies, or high market prices, and they are announced day-ahead. Nine to 12 peak days are called each year, and they can occur on any day of the week. On peak days, electricity costs increase from 2-6 pm or 12-6 pm, depending upon the PDP rate schedule that the C\&I facility is on (facilities receive financial incentives for participating for six hours instead of four hours). Customers stay on an existing TOU tariff and peak energy charge (e.g., \$1.20/kilowatt-hour [kWh]) is added to existing energy costs during peak hours on peak days. Large customers have a hedging option (through capacity reservation, on which they do not pay peak prices) to reduce electricity bill volatility. Small and medium customers can opt out on certain event days (e.g., every other event, consecutive events) without price penalty (PG\&E 2010b).

3. Southern California Edison's (SCE) Critical Peak Pricing (CPP) Program for medium/large ( $>200 \mathrm{~kW}$ ) C\&I facilities: Peak days are announced day-ahead when the system-level demand for power or the wholesale electricity price is very high, usually during hot summer days. Up to twelve CPP events are announced each summer, on weekdays only. Southern California Edison offers two CPP tariffs: CPP-Volumetric Charge Discount (VCD) and CPP-Generation Capacity Charge Discount (GCCD). For 
CPP-VCD, in exchange for lower partial-peak and on-peak energy prices on non-peak days, energy prices on peak days are raised to three times the normal partial-peak rate from 12-3 pm and five times the on-peak rate from 3-6 pm. For CPP-GCCD, energy prices are raised to 14 times the normal rate from $12-6 \mathrm{pm}$ in exchange for elimination of on- and mid-peak demand charges (SCE 2010a).

4. San Diego Gas and Electric's (SDG\&E) Critical Peak Pricing Program for C\&I facilities (> $20 \mathrm{~kW}$ ): Up to 18 peak days can be called each year (any time of the year, any day of the week). Events are announced day-ahead and triggered based on system load, weather, or utility or CAISO emergencies. In exchange for lower rates on non-peak days, peak-day energy prices are high $(\sim 1 / \mathrm{kWh})$ during the event period: $11 \mathrm{am}-6 \mathrm{pm}$ (SDG\&E 2010a).

5. New York Con Edison's Real-Time Pricing Tariff for large ( $>1500$ kW) C\&I facilities: Customers on Con Edison's RTP tariff are billed using hourly electricity prices that reflect hourly charges in wholesale energy rates. The New York ISO (NYISO) issues hourly (24-hour) wholesale prices day-ahead. Con Edison relays the hourly wholesale prices to its customers via the Internet (Con Edison 2010).

Several California utilities currently or plan to offer a Peak-Time Rebate (PTR) program. An SDG\&E residential PTR program offers bill credits to customers for load reduction during a PTR event. The load reduction is measured using a baseline, which is calculated based on historical consumption (SDG\&E 2010b). A certain minimum load reduction may be necessary to receive bill credits. For example, a customer with baseline of $100 \mathrm{~kW}$ with current load of $120 \mathrm{~kW}$ will have to shed more than $20 \mathrm{~kW}$ for any bill credits. Providing economic savings data in real time requires tracking a customer's baseline energy consumption against a measurement of their actual energy consumption, in order to compute their load reduction. Currently, such real-time information is not widely available to customers.

A simplified version of the OpenADR real-time pricing data model could be used to automate PTR events. While automation would provide information about notification, start and end time of the PTR event, the OpenADR data models developed in this study do not accommodate actual/baseline energy consumption data. Instead, the focus was on accommodating dynamic prices. Therefore, facilities using OpenADR participating in PTR would not be able to compute economic savings in real-time. Although expanding OpenADR data models to allow them to accommodate actual/baseline energy consumption data was outside of the scope of this study, it would be worthwhile to pursue in the future.

\subsection{Wholesale Electricity Market Information Systems}

Several wholesale electricity markets were also examined to understand how wholesale electricity prices and related information are published. Wholesale electricity market pricing information systems studied include the following:

1. California Independent System Operator: CAISO publishes day-ahead, day-of, and real-time energy and ancillary services (A/S) prices for the wholesale market. These prices are published as real-time Internet feeds in standardized data formats (e.g., text comma separated values [CSV] and eXtensible Markup Language [XML]) using Open Access Same-time Information System (OASIS) (CAISO 2010). 
2. Independent System Operator - New England: ISO-NE publishes hourly data, fiveminute data, and other market data (e.g., ancillary services) for the wholesale market on their website. All price data is also available for download as CSV files (ISO-NE 2010).

3. New York Independent System Operator: NYISO publishes day-ahead, hour-ahead, real-time, and ancillary services pricing data for the wholesale energy market in CSV, PDF, and HTML files available on their website (NYISO 2010).

\subsection{OpenADR Dynamic Pricing Technology Architecture}

After analysis of dynamic pricing programs and wholesale electricity market information systems, the elements of dynamic prices and its applicability to California dynamic pricing tariffs were determined. CAISO's wholesale market prices (as a proxy for an RTP tariff) and PG\&E's PDP rates (as a peak pricing tariff and as a proxy for TOU pricing tariff) were used. The technology architecture for dynamic pricing program interfaces was developed using OpenADR version 1.0 specifications that define DR program interfaces (Piette et al. 2009).

\subsubsection{OpenADR Version 1.0 DR Program Interfaces}

Most of the DR programs across the United States are broadly classified as reliability-based (includes emergency) and price-based programs. The OpenADR version 1.0 specifications were designed to support both price- and reliability-based DR programs. They also support a common DR communication data model between the electricity-service provider (e.g., utility or ISO) and the facility (e.g., C\&I) using three existing groups that interface with the Demand Response Automation Server (DRAS). Figure 1 below shows these three groups:

1. Utility or ISO operator interfaces

2. Participant operator interfaces

3. DRAS client interfaces

The interfaces define how the DR-related information is exchanged between the utility information systems (UIS) and the participants using a secure Internet. The electric utility or ISO and participant operators use the graphical user interface (GUI) to send and receive the information. The application programmer interface (API) is available for the DRAS clients (e.g., C\&I) to interface with the UIS to receive simple and/or smart client information. Participants can configure information such as notification, profiles, mapping, etc. Depending on the specific implementation of DR program interfaces, the stand-alone OpenADR system can be fully integrated with the electric utility or ISO OpenADR interface.

Utility / ISO Operator Interfaces

\begin{tabular}{|c|c|c|}
\hline Utility or ISO Operator GUI & & $\begin{array}{l}\text { OpenADR API (Data } \\
\text { Models) }\end{array}$ \\
\hline $\begin{array}{l}\text { Program Operator } \\
\text { - Web Client to DRAS } \\
\text { Utility Information Systems }\end{array}$ & $\begin{array}{l}\text { Secure } \\
\text { Internet }\end{array}$ & $\begin{array}{l}\text { Participant Manager } \\
\text { - Interfaces via DRAS UI } \\
\text { - Notifications } \\
3^{\text {rd }} \text {. Party Notifications } \\
\text { DR Program Profiles } \\
\text { Mapping Structure }\end{array}$ \\
\hline
\end{tabular}

DRAS Client Interfaces

OpenADR Client

OpenADR Clients

- Simple Client Information

- Smart Client Information

End-Use Sectors

- Commercial and Industrial

Figure 1. OpenADR Version 1.0 Utility or ISO, and Customer Interfaces to DRAS 
This study used these interfaces for dynamic pricing elements. The term OpenADR client is used instead of DRAS client to be consistent with the wide-scale current use of term OpenADR.

\subsubsection{Dynamic Pricing Elements}

The dynamic pricing programs were used to define elements to interface with existing OpenADR groups. These three interface groups were used in the technology architecture to communicate dynamic prices as follows:

1. The "Utility or ISO Operator OpenADR Interface" lists pricing schedules for both dynamic and TOU pricing models.

2. The Utility or ISO "Standalone OpenADR System" API is used to create dynamic pricing profiles and mapping structures to send a common DR signal to the facilities. The "Participant (Facility) Operator Interface" will receive and track dynamic prices, configure the mapping structure and notifications (e.g., e-mail) and other customizations.

3. The "OpenADR Client Interface" supports an OpenADR client that uses both the simple and smart client information for different end-use sectors.

\subsection{Pricing Schedules}

This study developed pricing schedules for three pricing structures, namely, RTP, Peak Pricing, and TOU Pricing (Table 1 below). The prices used for the technology demonstration and OpenADR interfaces were from CAISO and PG\&E, as listed in Table 1 below.

Table 1. Source of Prices Used for Each Pricing Schedule

\begin{tabular}{|c|c|}
\hline Pricing Structure & Source of Prices Used for Technology Demonstration \\
\hline Real-Time Pricing (RTP) & CAISO's Wholesale Energy Market Prices \\
\hline Peak Pricing & PG\&E's PDP Retail Rates \\
\hline Time-of-Use (TOU) Pricing & PG\&E's PDP Retail Rates \\
\hline
\end{tabular}

While the source of the prices used for the peak pricing schedules was an actual peak pricing rate (PG\&E's PDP retail rate), the sources of the prices for the RTP and TOU schedules were not comparable pricing structures. Instead, the TOU pricing schedule was built with prices from PG\&E's PDP retail rate since TOU tariffs are structured much like PDP rates, except that prices do not change day to day. The RTP pricing schedule was built with wholesale electricity prices published on CAISO's OASIS. We used the CAISO wholesale energy market prices for the RTP demonstration because OASIS is the only California system we have seen that uses automated real-time Internet feeds to publish easily accessible electricity prices. We anticipate that most market-based retail electricity pricing programs will use real-time Internet or similar feeds in the future. Therefore, using CAISO wholesale energy market prices allowed us to demonstrate a system in which OpenADR integrates with OASIS and extracts dynamic prices from real-time Internet feeds. The ability of OpenADR to integrate with real-time feeds will likely have wide applicability in the future.

The OpenADR data model was developed to accommodate each pricing schedule, including prices that are published both day-ahead (DA) and day-of (DO). Each pricing structure is discussed in depth in the following subsections. 


\subsubsection{Real-Time Pricing (RTP)}

Real-time electricity prices vary throughout the day as a function of environmental conditions (e.g., outdoor air temperature) and/or electricity supply and demand conditions. Two methods of acquiring RTP schedules were developed:

1. Manual Entry Interface: The utility or ISO operator through a GUI manually enters hourly real-time prices and publishes it DA or DO.

2. Real-Time Internet Feed: Real-time prices are extracted from real-time Internet feeds, as described previously. Specifically, the Web service from CAISO's OASIS for both DA and DO wholesale electricity pricing was used to create an OpenADR-compliant RTP data model (also in Web services). Web services use XML for data communications.

The benefit of manual entry is that the utility operator has some flexibility to issue customerdirected dynamic pricing rates. An RTP schedule using manual entry was also developed for an OpenADR demonstration project with residential pricing schedules (described in Section 4.0), communication technologies, and related devices (Herter et al. 2008; Herter et al. 2009; Herter et al. 2010). Using real-time Internet feeds allows for automation with utility- or ISO-published prices and integration with its systems.

We considered several different ways to structure an RTP tariff for DO and DA prices using manual and real-time Internet feeds, including the following:

1. Day-ahead RTP (DA-RTP): Prices are set day-ahead and take effect for the next day.

a. Hourly DA-RTP (24 prices/ day): Hourly prices for the entire next day are published day-ahead. Both SCE's RTP tariff and Con Edison's RTP tariff work this way.

b. 15-Minute DA-RTP (96 prices/ day): Fifteen-minute prices for the entire next day are published day-ahead. Fifteen-minute prices give more resolution than hourly prices and, possibly, enable better management of energy costs within facilities that can handle such granular price representations. We have not seen an example of this tariff structure in retail or wholesale electricity markets.

2. Day-of RTP (DO-RTP): Prices are set hourly (or every $x$-minutes) directly before they take effect on the same day.

a. Hourly DO-RTP (one price/hour): Directly before every hour one price is set for the next hour. We have not seen an example of this pricing structure in the retail electricity market; however, this is a common pricing structure for wholesale markets. For example, ISO-NE's hourly locational marginal Prices (LMPs) are published one price/hour for each node/zone (ISO-NE 2010).

b. Hourly, 15-minute interval DO-RTP (four prices/hour): Directly before every hour, four 15-minute interval prices are set for the next hour. We have not seen an example of this tariff structure in retail electricity markets, but at least one California A/S market works this way as discussed in Table 2 below.

c. Every $x$-minute DO-RTP (one price/x-minute): Directly before every $x$-minute period one price is set for the next $x$-minute period. This is a generalization of $2 a$ above. We have not seen an example of this pricing structure in the retail 
electricity market; however, this is a common in wholesale markets. Common intervals include $\mathrm{x}=5$ minutes and $\mathrm{x}=15$ minutes.

For the purposes of technology demonstration, we selected two structures for which we developed our preliminary RTP data models: Hourly DA-RTP and Hourly 15-minute interval DO-RTP. All other tariff structures can be represented with very similar data models. For example, using the same model developed for Hourly DA-RTP, 15-minute prices can be represented instead of hourly prices if the number of prices/day is increased from 24 to 96 .

As mentioned previously, CAISO's wholesale energy market prices were used to integrate OpenADR with real-time Internet feeds. As shown in the Table 2 below, CAISO publishes many wholesale energy prices at different time intervals (CAISO 2010). Each set of prices belongs to a certain market, among them DAM (Day Ahead Market); RUC (Residual Unit Commitment); and RTM (Real Time Market). Prices are published daily, hourly, or every $x$ minutes, and the publication interval indicates when the prices are published relative to when they take effect, either 1 pm (13:00) DA or T-y minutes where $T$ is the start of the next interval. This study used CAISO's DAM locational marginal price (LMP) for the Hourly DA_RTP pricing schedule and CAISO'S DO hour-ahead scheduling process (HASP) LMP for the Hourly, 15-minute interval DO-RTP. These relevant tariffs are highlighted in Table 2 below.

Table 2. CAISO Wholesale RTP Programs via OASIS (Adapted from CAISO 2010)

\begin{tabular}{|l|l|l|l|}
\hline Price & Market & Publication Type & Publication Interval \\
\hline LMP & DAM & Daily & $13: 00$ \\
\hline LMP & RUC & Daily & $13: 00$ \\
\hline Interval LMP & RTM & Every 5 minutes & T-2.5 minutes \\
\hline HASP LMP & HASP & Hourly & T-45 minutes \\
\hline A/S Clearing Prices & DAM & Daily & $13: 00$ \\
\hline Interval A/S Clearing Prices & HASP & Hourly & T-45 minutes \\
\hline Clearing Prices & RTM & Every 15 minutes & T-5 minutes \\
\hline
\end{tabular}

\subsubsection{Peak Pricing}

In peak pricing tariffs, electricity prices on peak days are different than electricity prices on nonpeak days. Prices are generally preset; however, the consumer does not know if a certain day will be a peak day or a non-peak day until day-ahead or day-of. Peak days are called as a function of environmental conditions (e.g., outside air temperature), and/or electricity supply and demand conditions. We studied a representative peak-pricing schedule from PG\&E's PDP pricing program, as the development of OpenADR data models for PDP is closely aligned to its automation goals for use of OpenADR in the 2010 automated DR program.

To facilitate the OpenADR RTP data models for peak pricing, the study evaluated PDP A-1 and A-6 rate schedules for small commercial customers with demand below $200 \mathrm{~kW}$ and PDP E-19 and E-20 rate schedules for large C\&I customers with demands greater than $499 \mathrm{~kW}$ and $999 \mathrm{~kW}$, respectively. The PDP A-1 and A-6 rates track closely with residential rates. These PDP rate schedules include information for peak price and TOU rates and are an adder to TOU rate for both summer and winter seasons. While the A-1 and A-6 rates exclude demand charges and energy rates, the E-19 and E-20 rates have demand charges and energy rates (PG\&E 2010a; PG\&E 2010b). 
The PDP rate schedules for small and large C\&I customers are similar in structure but vary in rate information. These peak pricing rates would constitute a good starting point for PDP-based DR events for large C\&I and its representation (e.g., demand charges and energy rates) using the same OpenADR RTP data models.

\subsubsection{Time-of-Use (TOU)}

Time-of-use pricing is defined here as electricity pricing in which the consumer knows their electricity prices more than a day in advance, though the prices can vary throughout different time intervals. The time intervals can be based on time of day (peak, part-peak, off-peak, etc.), day of week (weekday vs. weekend), and season (summer vs. winter). A TOU price structure could be intended to reduce electricity usage during peak periods or encourage facilities to shift usage from peak to off-peak periods for price and reliability reasons.

The TOU prices are pre-set and the utility publishes the TOU price schedule for a certain period of time (e.g., for the next year). Hence, customers know their electricity costs well into the future. TOU pricing structures are very similar to peak pricing structures except that electricity prices are always known; unlike with peaking pricing tariffs there is no uncertainty about whether tomorrow will be a peak day or not. Therefore, TOU schedules could use the same data model as peak pricing schedules. This study used PDP rates to develop a TOU pricing structure.

\subsection{Summary}

Given the pricing schedules and elements required for RTP, Peak Pricing, and TOU, one underlying comprehensive data model will suffice for dynamic pricing signals. Considering that the RTP schedule potentially requires the largest number of elements, we have developed a data model capable of handling an RTP pricing structure. This model is used as the basis to represent both peak pricing and TOU schedules and relevant information. 


\subsection{Dynamic Pricing Development for Demonstration}

After evaluating the OpenADR interfaces and elements of dynamic prices discussed in the previous section, data models for dynamic prices were developed using OpenADR technologies. This section describes how OpenADR specifications were used to develop a RealTime Pricing (RTP) data model and graphical user interfaces (GUIs). Real-time prices published using OpenADR were represented with both simple and smart client information for day-ahead (DA) and day-of (DO) pricing schedules. We also analyzed how peak pricing and time-of-use (TOU) pricing schedules could be represented using the same data model as that developed to represent RTP signals.

\subsection{Dynamic Pricing Interfaces and Technology Architecture}

The elements of dynamic prices identified earlier were applied to OpenADR interfaces and technology architecture. As shown in Figure 2 below, these interfaces are used as follows:

1. The "Utility or ISO Operator OpenADR Interface" lists pricing schedules for both dynamic and TOU pricing models. This interface allows the following functionalities using a GUI, called the "Utility dashboard" or "ISO dashboard":

a. Configure participant (customer) accounts.

b. Send OpenADR-compliant messages (pricing models) that contain prices and schedules to the participating customers such as C\&I, residences, and others.

c. CAISO OASIS real-time Internet feeds for both DA hourly prices and DO 15-minute prices.

2. The Utility or ISO "Standalone OpenADR System" API is used to create dynamic pricing profiles and mapping structures to send a common DR signal to the facilities.

3. The participant operator has interfaces with the OpenADR system to allow the following functionalities using a GUI, called the "Participant Dashboard."

a. The Participant Dashboard is used to monitor whether an OpenADR signal is being sent from the OpenADR system, monitor the time-of-day prices that are specified using the OpenADR signal, and set the rules that map the actual prices into simple client information. This information is sent using the OpenADR signal.

b. The participant operator can view prices on the Participant Dashboard, which enables operational planning in response to dynamic prices.

4. The "OpenADR Client Interface" supports an OpenADR client that uses both the simple and smart client information. This information can be used by different end-use sectors, such as C\&I and residential. 


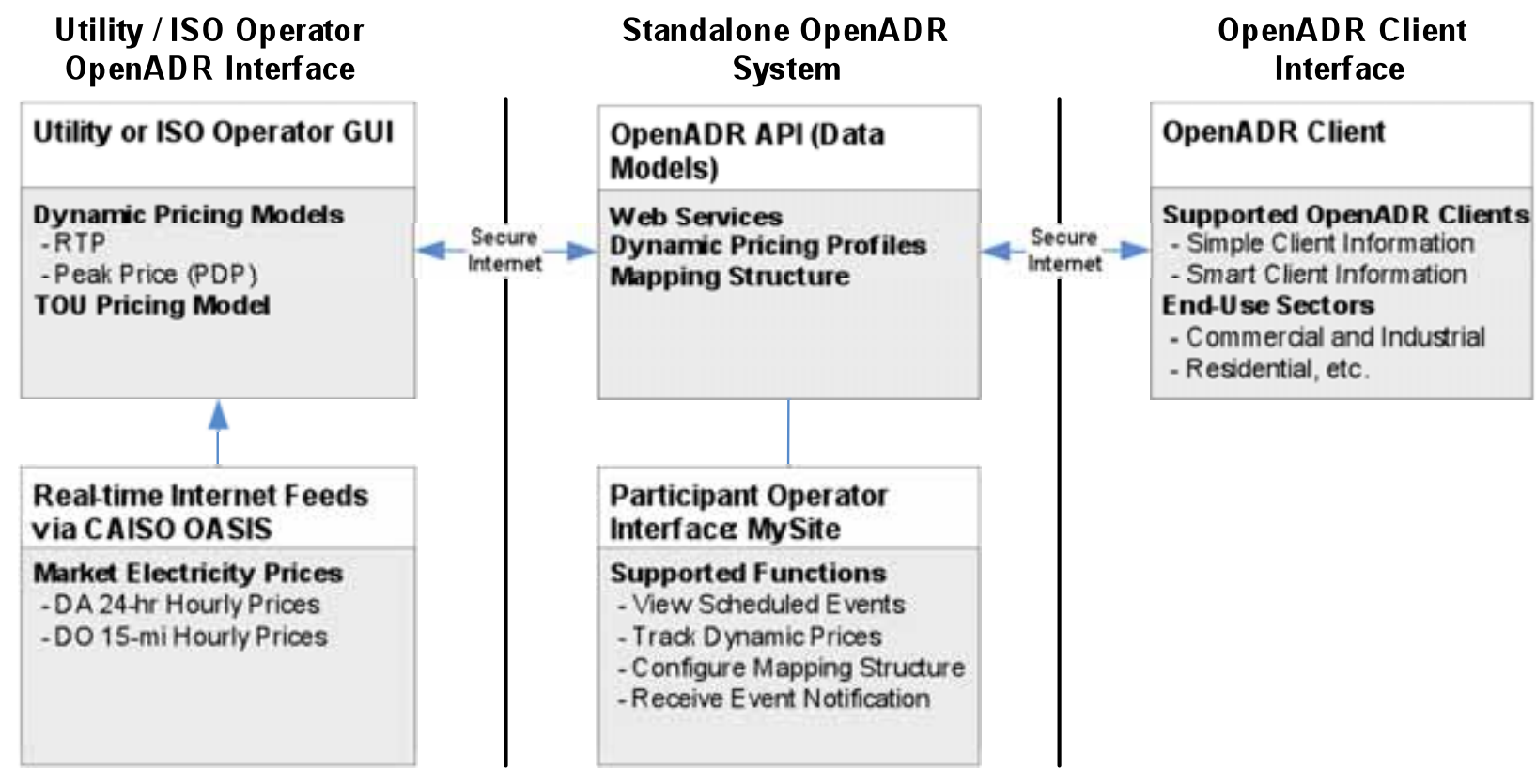

Figure 2. Technology Architecture of OpenADR Utility or ISO Interfaces for Dynamic Pricing

\subsection{Dynamic Pricing System}

OpenADR for dynamic pricing uses the same stand-alone OpenADR system, as do California commercial automated DR programs. The OpenADR system GUIs for the utility or ISO, the participant operators, and the OpenADR client were developed further for dynamic prices. Screen shots of the OpenADR interfaces are shown and described in Appendix B.

Figure 3 below shows the structure of the OpenADR dynamic pricing system. It also shows client interfaces for C\&I and residential customers. The RTP data models demonstrate the dynamic pricing profiles for OpenADR clients using both smart and simple client information. Commercial and industrial facilities could use smart and/or simple client information depending on the types of systems (sophisticated or legacy). Providing simple client information ensures backward compatibility to existing DR programs. The residential demonstration uses "Bridge Clients" at the radio sub-station (Herter et al. 2010). A Bridge Client translates Internet-based OpenADR RTP information into RTP profiles (price schedules and tiers) to broadcast using radio communications. Programmable communicating devices (PCDs) within residences can use these RTP profiles to shed loads and display price information. 


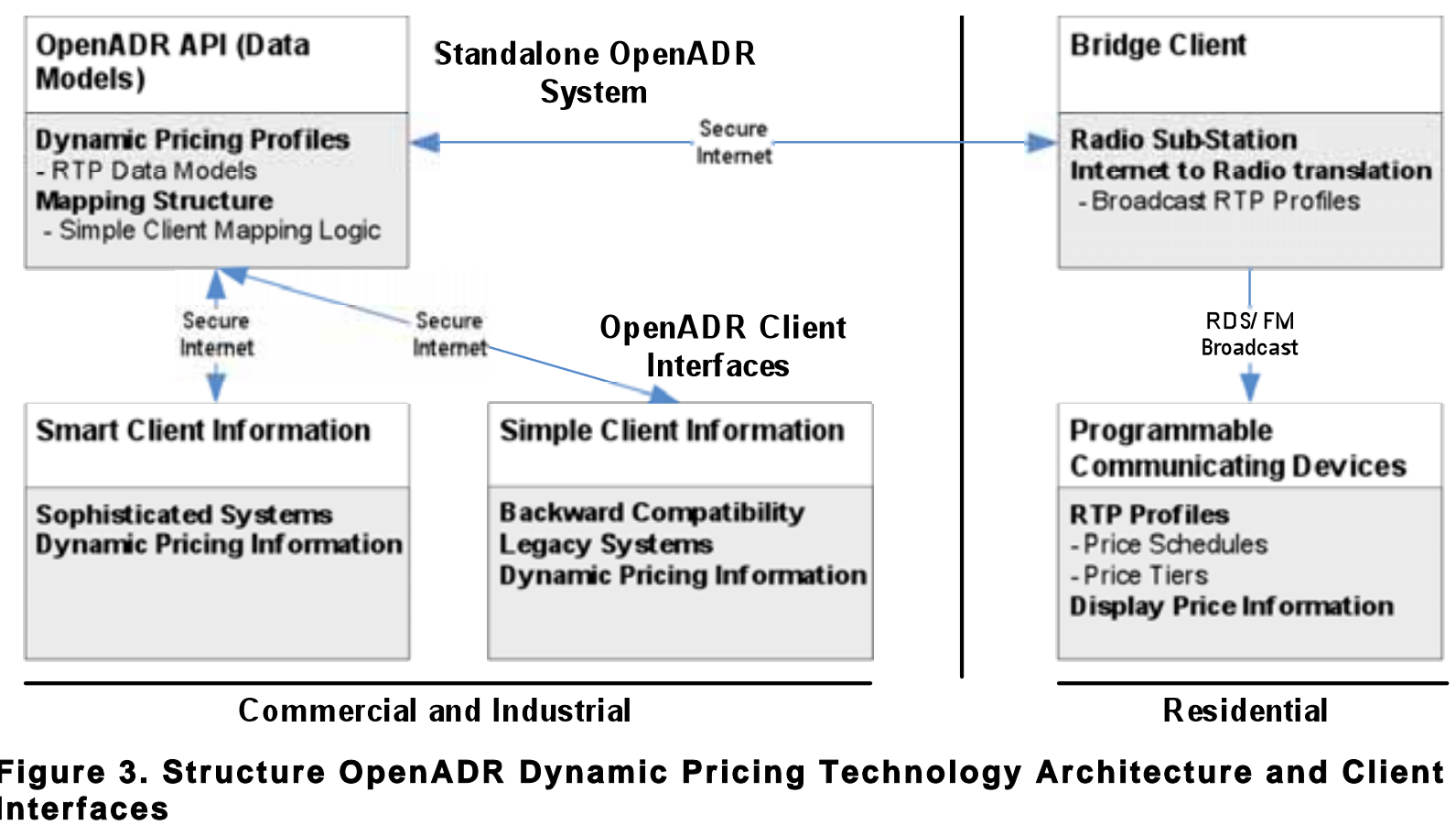

\subsection{Data Model Development}

OpenADR dynamic pricing data models utilize OpenADR data models and programs to represent and send price information. The following information must be determined in order to use OpenADR for a particular dynamic pricing program:

- Overall time period that the prices apply (e.g., entire day or some specific time period in the middle of the day). This is used to specify the start and end time for the DR event that is specified in the OpenADR signal.

- Whether the time period is broken up into a schedule of prices and, if so, the resolution of the time slots. OpenADR is very flexible in allowing arbitrary schedules of time periods and can easily accommodate varied time periods (e.g., hourly, 15-minute).

- The type of price information to be sent. OpenADR currently supports three different types of price information:

1. Absolute Prices (PRICE_ABSOLUTE): The price data specified in the OpenADR signal is the actual price for the electricity. This type of price information was used to represent real-time prices.

2. Relative Prices (PRICE_RELATIVE): The price data specified in the OpenADR signal is relative to the customer's current rate; for example, " +0.15 " would mean that their rate is increased by 0.15 cents from their normal rate. This type of price information was used to represent Peak Day Pricing (PDP) and TOU pricing.

3. Price Multipliers (PRICE_MULTIPLIER): The price data specified is some multiple of the customer's current rate. For example "3.0" would signify that the customer's price had increased by a factor of three. This type of information was used to represent CPP. 
Within the OpenADR dynamic pricing data models, different dynamic pricing programs can use these types of price information. The following subsections give more details on how the OpenADR data models were developed for each type of dynamic pricing program.

\subsection{RTP Data Model}

The OpenADR RTP data model was modeled on California Independent System Operator's (CAISO) real-time market price models using the Open Access Same-time Information System (OASIS). An example of a representative OpenADR client interface data model for a day-ahead hourly RTP using eXtensible Markup Language (XML) is shown and described below. ${ }^{2}$

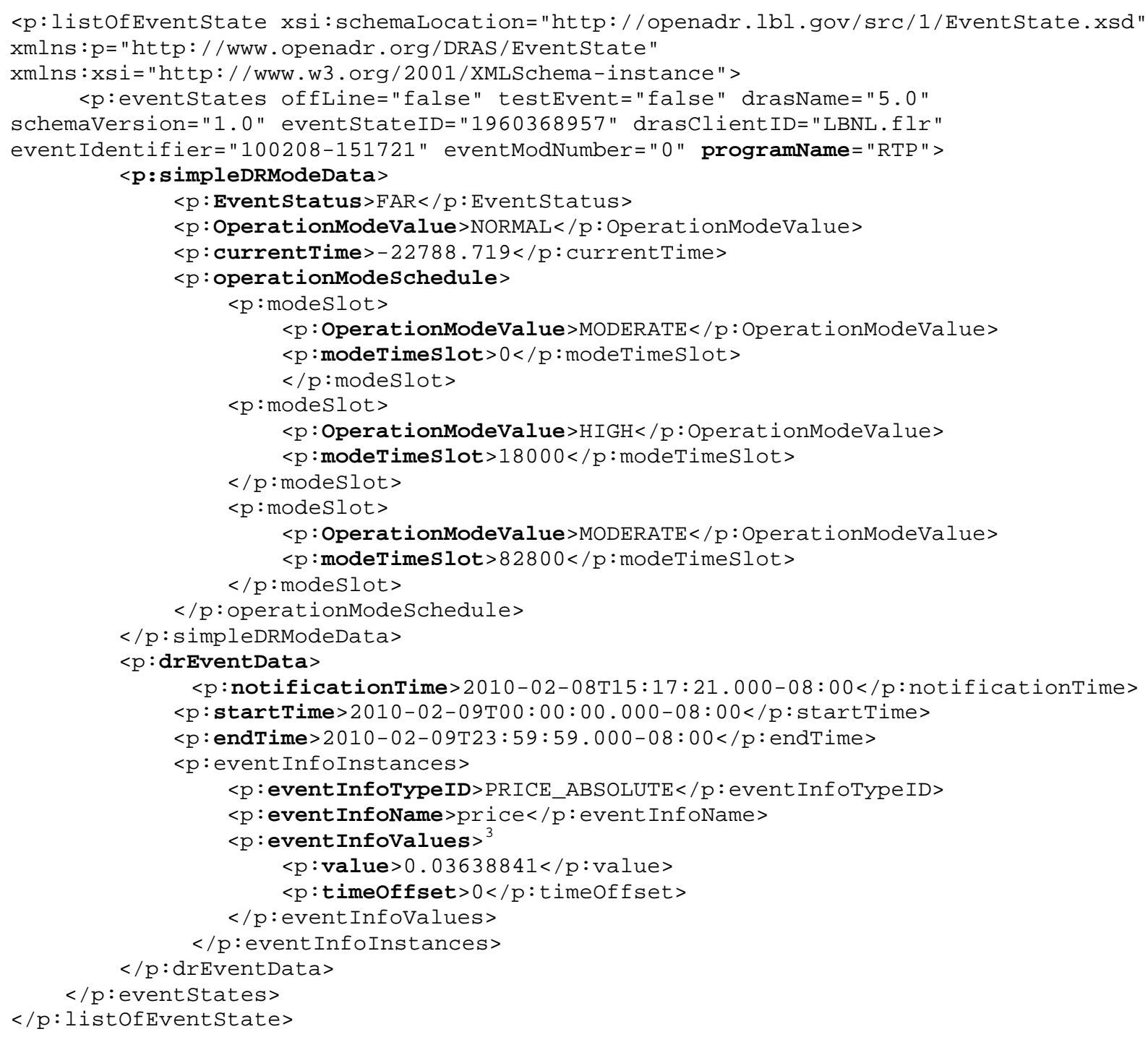

${ }^{2}$ The fields in bold are explained following the representative OpenADR data model. The tables and data models for CAISO wholesale real-time market prices are described in Appendix C.

${ }^{3}$ Only one of the 24 eventInfoValues field is shown for an RTP event of 24-hour duration. This field could be extended to 96 prices/day (e.g., 15-minute prices), depending on specific RTP program requirements. 
The OpenADR dynamic pricing data model contains the XML representation of metadata such as location, version of data models (called schemas), DR program, client identifiers, program name (e.g., RTP, PDP , CPP), and more. Following the metadata, the OpenADR data model is split into two main sections, described as follows:

1. simpleDRModeData: This section contains all the information concerning the translation of the actual prices into simple client information

2. drEventData: This section contains detailed information about the schedule of price signals (smart client information).

The first section, simpleDRModeData, contains the following key fields.

- EventStatus: This signifies whether the OpenADR schedule of prices is pending (i.e., FAR or NEAR) or whether they are currently ACTIVE.

- OperationModeValue: The current simple operation mode value (e.g., Normal).

- currentTime: A relative time from the beginning of the event for when this particular OpenADR message was generated.

- operationModeSchedule: A schedule of simple operation mode levels specified in the form of a list of modeSlots that has the following fields for each entry:

- OperationModeValue: The actual simple mode level (e.g., Normal, Moderate, High).

- modeTimeSlot: The relative time offset from the event startTime in seconds. This time signifies when the time slot for this value ends and when the time slot for the next value begins.

The second section, drEventData, contains the following key fields:

- notificationTime: The date and time that the facility is notified of the price schedule.

- startTime: The date and time that the price schedule starts.

- endTime: The date and time that the price schedule ends.

- eventInfoTypeID: The type of prices contained in this OpenADR RTP signal, as discussed above. In this example, the prices are represented with PRICE_ABSOLUTE.

- eventInfoName: The name given to the data for this program. In this example, it is defined as "price."

- eventInfoValues: A list of actual prices that determine the schedule of the prices. Each price in the schedule is specified by the following values:

- value: Actual price value.

- timeOffset: Relative time offset from the event startTime in seconds. This time signifies when the time slot for this value ends and when the time slot for the next value begins. For example, the next time slot value can specify the end of the time slot for general DR event information in the value field. In the non-default cases, the "offset" value could be added to describe the time interval representation (e.g., seconds, milliseconds). 
The unit for price value is currently in dollars and cents to simply represent a price. How that price is tied to other attributes associated with the energy is specific to the DR program and not specific in the schema (e.g., \$/kWh). More sophisticated ways of representing energy attributes (e.g., source of generation) in a standardized model are being developed by various standards development organizations (OASIS SDO 2010a; OASIS SDO 2010b) and user groups (Open Smart Grid Users Group 2010). When such standardized models are available, the simple price that currently exists in OpenADR may be replaced by a more rich representation and attributes.

\subsection{Peak Pricing and TOU Pricing Data Models}

The OpenADR RTP data model is an example of a common representative data model that could be used by a utility or ISO to send dynamic pricing information to facilities' EMCS and end-use devices. This section evaluates the use of the RTP data model described in the previous section for use with peak and TOU pricing tariffs. We show that one common pricing model can be used to represent dynamic pricing programs. However, this model for peak and TOU pricing tariffs has not yet been implemented.

Appendix D includes PDP rate schedules for small and large C\&I customers used to create the peak and TOU pricing schedules.

\subsubsection{Using the RTP Data Model for Peak Prices}

Based on Pacific Gas and Electric Company's (PG\&E) PDP rate description, we found that the E-20 rate schedule has the most diverse information. The elements used in the OpenADR RTP data models can be used to represent information within such a peak pricing program. The E-20 rate schedule information can be represented using the OpenADR RTP data models as follows:

1. Peak Pricing Program Information (Metadata): In the current RTP data model, the program information (Metadata) that contains the program name field could be used to specify the peak pricing program and related rate schedule (e.g., PDP-E20).

2. Peak Pricing Common Elements: The peak pricing program name and rate schedule contains the following common elements that are also associated with drEventData in RTP data model:

- Program Type (e.g., day-ahead or day-of): This is represented by notificationTime.

- Peak Usage Period (e.g., 2-6 pm): This is represented by startTime and endTime.

- Peak Usage Rates (e.g., \$/kW).

- Time Intervals (e.g., 60- or 15-minute).

- Date and Time (e.g., 2009.07.07 12:00 pm): These are represented by eventInfoValues and timeOffset.

3. Additional Information: The additional peak pricing information such as "Demand and Energy Rates" for seasons (such as summer, winter, summer and winter, etc.) and rate periods (e.g., On-peak, Part-Peak, Off-peak), voltage, etc. will not be necessary if the facility strategies are price-based and/or determined during the period of enrollment in DR programs.

Any other information is usually part of the utility contract with the facility or included in other OpenADR interfaces and can be excluded from the OpenADR client interface used to represent peak pricing. Examples are the utility or ISO name (e.g., PG\&E), market type (e.g., retail or 
wholesale), customer types (e.g., small commercial), demand (e.g., < $200 \mathrm{~kW}$ ), location, (e.g., zones, latitude/ longitude coordinates, nodes), and customer charge (e.g., \$/kWh) for both single-phase service and poly-phase service per meter/day. These are specific to a particular peak-pricing program.

Considering that the current PG\&E peak day pricing rates have scheduled DR event periods (e.g., start at $2 \mathrm{pm}$ and end at $6 \mathrm{pm}$ ) and one price level (e.g., $\$ 1.20 / \mathrm{kWh}$ ), which is an adder during this period; the price type representation that is most relevant would be "PRICE_RELATIVE." ${ }^{4}$

\subsubsection{Using the RTP Data Model for TOU Prices}

The TOU prices use the same structure as peak pricing (e.g., usage period, season, price) except that the prices are static day to day. Therefore, the same data model used for peak pricing can also be used for TOU pricing. The specific TOU rate schedule name can be represented similarly as PDP rate schedule names.

\subsection{Summary}

A simple and comprehensive OpenADR data model can support different dynamic pricing schedules (e.g., real-time pricing, peak pricing, and TOU pricing). Common data models facilitate easy transition of customers from one dynamic pricing program to another. The implications of such a common data model on DR programs, resulting policies, and facility responses (e.g., DR strategies) needs further research. For example, on May 1, 2010, PG\&E critical peak pricing customers will be migrated to PDP rates. While a common data model will facilitate this transition, facility response strategies may need to make changes since:

- CPP events last six hours while PDP events usually last four hours. Facilities doing global temperature adjustment over six hours in the CPP program may change their strategies to do the same or similar level of adjustment over a shorter period of time for the PDP program. Some facilities may be willing to shed more load, since PDP events are shorter.

- The CPP program has two price periods (moderate and high), while PDP has one.

- For a facility using smart client information, the PDP price type information will be "PRICE_RELATIVE," instead of "PRICE_MULTIPLE" and may indicate program type.

\footnotetext{
${ }^{4}$ Commercial CPP programs at California utilities use price type representation of "PRICE_MULTIPLE."
} 


\subsection{Strategies for Dynamic Price Mapping}

One way to simplify dynamic pricing signals is to map smart client information to simple client information. Such a translation allows mapping actual dynamic prices to simple "operation modes" such as normal, moderate, high, etc. OpenADR signals for dynamic pricing include both smart and simple client information. Simple client information is currently used by facilities in the California commercial Auto-DR programs such as Critical Peak Pricing (CPP) and Demand Bidding Program (DBP). This smart-to-simple mapping could be either external to the facility (e.g., utility or ISO OpenADR server) or internal to the facility (e.g., sophisticated control systems, gateway). Mapping prices to operational modes may facilitate wider customer participation in dynamic pricing tariffs because it eases facility or EMCS processing of dynamic pricing signals and carrier communications while also allowing for backward compatibility with existing CPP and DBP customers and their underlying strategies.

This section presents several scenarios for mapping dynamic prices to operational modes. Though outside of the scope of this study, in the future it will be necessary to:

1. Evaluate the likely use of information (operational modes and/or dynamic prices) by EMCS, end-uses, programmable communicating devices, etc.

2. Understand how best to execute DR strategies given operational modes and/or dynamic prices. This may include developing facility-level control strategies that aim to minimize energy costs over time.

Note that because pricing information is simplified in mapping dynamic prices to operational modes, facilities will be able to better manage their energy costs if they develop optimal control strategies based on actual dynamic prices. However, mapping allows facilities to reduce upfront programming and labor costs related to developing and maintaining optimal control strategies capable of using actual dynamic prices. Therefore, many existing or new facilities may opt to use operational modes instead of prices in order to simplify their control strategy design. A facility can always switch from using simple client information to using actual dynamic prices when desired.

This section covers two scenarios for mapping dynamic prices to operation modes (sent in one OpenADR message) to the facility:

Scenario 1: Absolute mapping of price ranges to operation modes.

Scenario 2: Relative mapping of prices to operations modes. This could be based on customer choices (e.g., duration a customer is willing to be in various operational modes), electricity price references (e.g., Average or High Price Reference, defined below), or electricity price indices (i.e., a number or percentages) derived from a customer's historical economics of energy use.

\subsection{Scenario 1: Absolute Price Mapping}

In two related OpenADR laboratory-based demonstration projects, prices were mapped to operational modes: 
1. California Energy Commission and Sacramento Municipal Utility District Project

2. Electric Power Research Institute Project

The California Energy Commission (Energy Commission) and Sacramento Municipal Utility District (SMUD) project used the Radio Data System (RDS) communication protocol over oneway frequency modulation (FM) to broadcast dynamic pricing information to residential devices (e.g., programmable communicating thermostats). The RDS allows transmission of small amounts of data (e.g., a price message) to a conventional FM radio (Herter et al. 2008; Herter et al. 2009). The Electric Power Research Institute (EPRI) project used the Internet to send OpenADR messages (mapped prices) to commercial, industrial, and residential systems and/or end-use devices (EPRI 2009).

\subsubsection{The California Energy Commission and Sacramento Municipal Utility District Project}

In the Energy Commission and SMUD project demonstration for the residential sector, a mapping structure translated hourly price schedules to simple price tiers or operation modes (e.g., moderate, high) using price ranges. The residential devices used the mapping structure and price schedules to execute pre-programmed response strategies. Figure 4 below illustrates this mapping of an hourly RTP schedule, developed in this study, to simplified information with start and end times. Both the price schedule and the mapped price tiers were sent to residential devices using RDS over an FM radio broadcast (Herter et al. 2010).

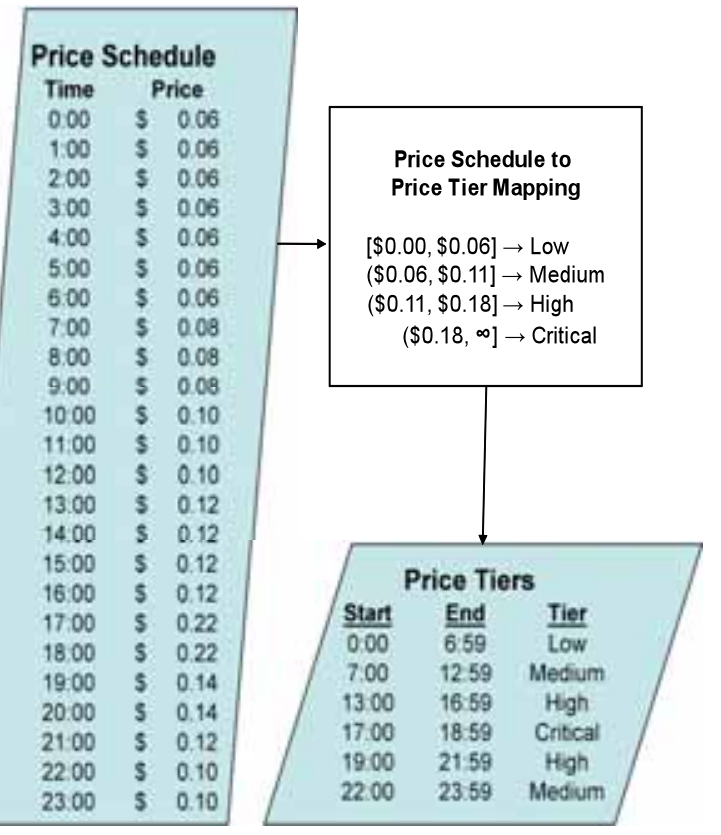

Figure 4. Hourly Price Schedule Mapping Developed for the SMUD Project

\subsubsection{Electric Power Research Institute Project}

The EPRI Project was a laboratory demonstration that used simple client information to represent dynamic prices using a price multiplier variable (similar to existing commercial CPP programs). The participants included C\&I and residential control vendors. As shown in Table 3 
below, the vendors used "price multipliers" provided by the OpenADR signals and translated them to "price" using a "base price $(\$ / \mathrm{kW})$. ." The "price" was mapped to operational modes using price ranges. The participating vendors implemented pre-programmed shed strategies for each operational mode. Optionally, the participating vendors were asked to display the translated price on a GUI using the formula (EPRI 2009):

$\$ / k W($ Display $)=$ CurrentPriceMultiplier * Base Price

Table 3. Participants Mapping Criteria for Price Multiplier to Price

\begin{tabular}{|c|c|c|c|}
\hline $\begin{array}{l}\text { Price Multiplier } \\
\text { (Current Price Multiplier field) }^{5}\end{array}$ & Price $(\$ / \mathbf{k W})$ & $\begin{array}{l}\text { Operation } \\
\text { Mode }\end{array}$ & Description \\
\hline $\begin{array}{l}\mathrm{x} 1 \text { or if there is no event and if no } \\
\text { information is provided in the } \\
\text { current price multiplier variable }\end{array}$ & $\begin{array}{l}\text { Base Price } \\
\$ 0.10\end{array}$ & & Do nothing. \\
\hline $\mathrm{x} 2$ & $\begin{array}{l}>\$ 0.20 \text { and } \\
<\$ 0.40\end{array}$ & $\begin{array}{l}\text { Moderate } \\
\text { Shed Event }\end{array}$ & $\begin{array}{l}\text { The client should execute a subroutine } \\
\text { that sheds } 25 \% \text { of the controllable loads. }\end{array}$ \\
\hline $\mathrm{x} 4$ & $>\$ 0.40$ & $\begin{array}{l}\text { High Shed } \\
\text { Event }\end{array}$ & $\begin{array}{l}\text { The client should execute a subroutine } \\
\text { that sheds } 75 \% \text { of the controllable loads. }\end{array}$ \\
\hline
\end{tabular}

The EPRI project used a base price and price multipliers (multiple of the base price) instead of real prices due to implementation constraints. At the time of demonstration, no resources were available to configure OpenADR system to send actual prices. Therefore, the EPRI project used a simpler price representation than the SMUD project, which used actual hourly prices.

Both the SMUD and EPRI projects have resulted in two potential ways that C\&I, and residential customers could use OpenADR dynamic pricing signals to reduce loads. These are also examples of how dynamic pricing signals can be sent using different technologies and network communications.

\subsection{Scenario 2: Relative Price Mappings}

Using absolute mappings of price ranges to operation modes may be too simplistic for electricity markets where price variability needs to be addressed. Long-term (and, possibly, short-term) changes in electricity costs could have significant impact on facility operations and business. In such cases, relative mappings can be used to link prices to operation modes, participation time, etc. The goal of using relative mappings is to provide flexibility to the facilities in mapping prices to operational modes.

For example, relative mapping is useful when electricity market prices rise over time. In this case, customers using absolute mappings will find that they are spending more and more time in high and/or moderate mode because, without explicit modification to absolute mapping, their price thresholds do not change with the changing cost of energy. This is illustrated in

\footnotetext{
${ }^{5}$ The price multipliers shown in the EPRI demonstration were not the same as those used in commercial PG\&E critical peak pricing program. This was intentional so that vendors could build logic to translate prices instead of using price multipliers to execute pre-programmed DR strategies.
} 
Figure 5, which includes both hypothetical average daily real-time prices and price duration curves for a facility in Year 1 (low energy cost year) and Year 2 (high energy cost year). Much like load duration curves, we have constructed the price durations curves by plotting each realtime price (from the average daily real-time prices plot) in order from most to least expensive. Transition prices (between normal/moderate and moderate/high) and their relative operation modes for both Year 1 and Year 2 are shown. Since the transition prices are fixed in an absolute mapping, the facility spends " $\mathrm{C}$ " hours (higher) in high mode in Year 2 instead of only " $\mathrm{A}$ " hours in Year 1. The facility spends "D minus $C$ " hours (lower) in moderate mode in Year 2 as opposed to "B minus A" hours in Year 1. This illustrates the need for dynamic mapping strategies that allow facilities to adjust their transition prices in response to price variations over time.

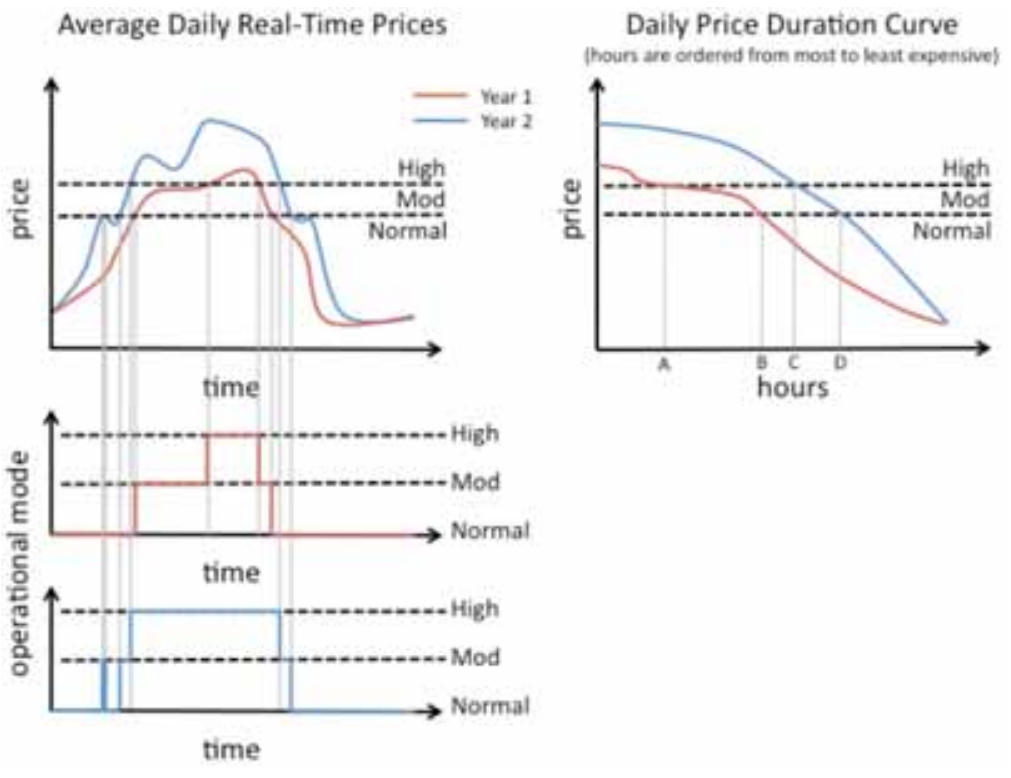

Figure 5. Average Daily Real-Time Prices and Price Duration Curves for a Low Price Year (Year 1) and a High Price Year (Year 2)

The following sections discuss the volatility of electricity prices and propose several early concepts to develop relative price mappings that could deal with price variability over time. Here, we only scrape the surface of the variety of methods that could be used to map prices to operational modes. Further studies to determine the best methods are recommended.

\subsubsection{Electricity Market Price Volatility}

Currently, in California, wholesale electricity price volatility is more significant than retail market price volatility because no market-based retail real-time pricing exists. Many economists recommend RTP tied directly to wholesale prices (Borenstein et al. 2002; Borenstein 2002; Bushnell et al. 2009). Dynamic prices could also be a function of the "value and price of electricity in different time periods" (DOE 2006), which implies that they could encapsulate information other than wholesale prices. Therefore, as a sample, this study examined price volatility in California's wholesale electricity prices, as it is expected to be a good proxy for possible future retail electricity price volatility. 
Figure 6 shows the wholesale price trend for approximately one year of day-ahead (DA) hourly locational marginal prices (LMPs) from one node in California (Anita_6_N001). This node is not meant to be representative of system-wide LMPs, which consists of thousands of nodes. Since the California Independent System Operator's (CAISO) Market Redesign and Technology Upgrade (MRTU) took effect in April of 2009, prior data is not available on Open Access Sametime Information System (OASIS). The daily minimum, maximum, and average prices are plotted. The average prices were fit to a line, which was used to determine the long-term price trend. There is clearly an upward trend in electricity costs. Between the start and end of the time interval shown (April 1, 2009 to February 18, 2010) the price of electricity increased by 111\% (\$24.68/MWh to $\$ 52.07 / \mathrm{MWh})$. Interestingly, at this node, there does not seem to be much seasonal variation in wholesale prices.

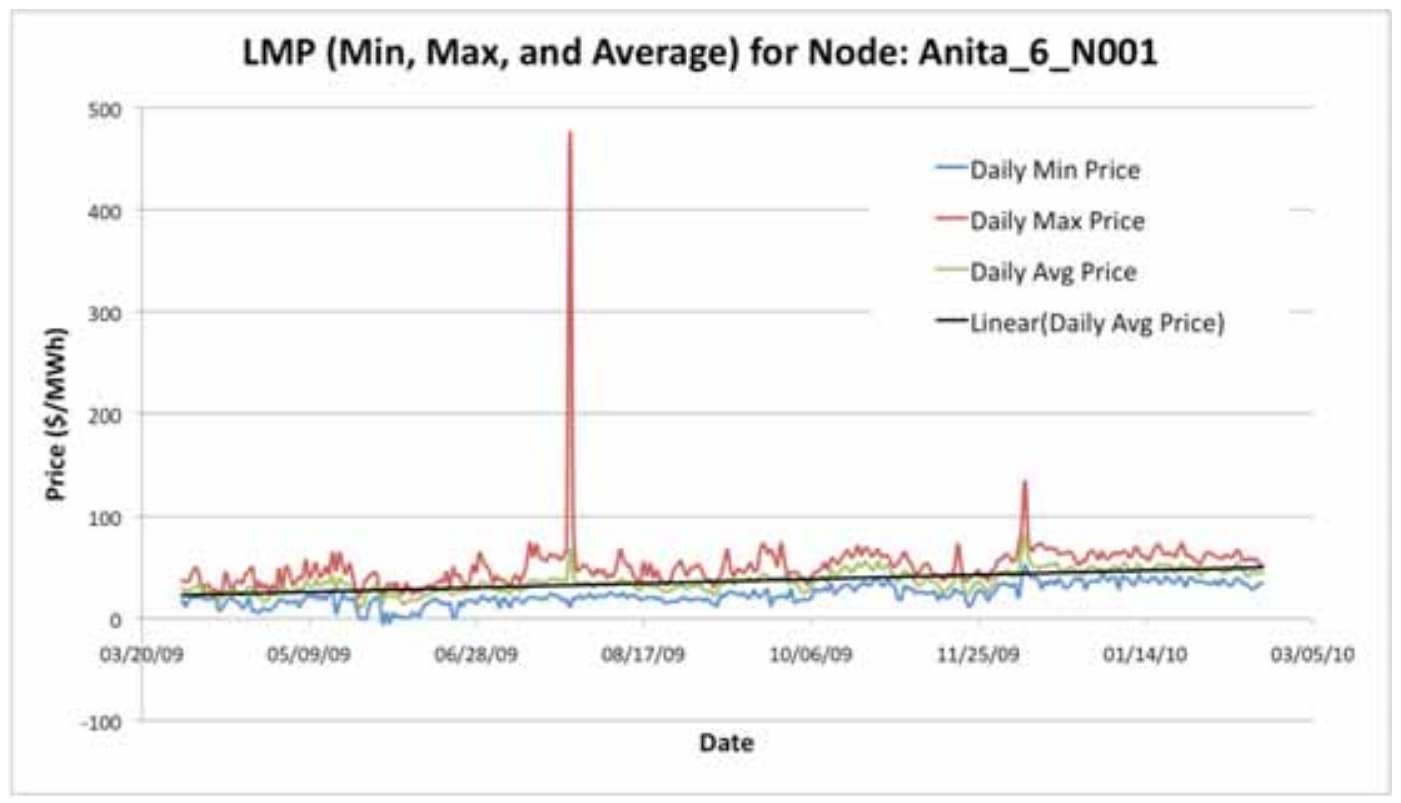

\section{Figure 6. CAISO Wholesale DA Hourly LMP for a Node}

There two noteworthy spikes, one in each of the summer and winter seasons. The July 26 (Sunday/Weekend) high spike could be due to unexpectedly high demand resulting from high outdoor air temperatures. A CPP event was called the next day on July 27 (Monday/Weekday), suggesting high temperatures around this time. High prices ( $>\$ 400 / \mathrm{MWh}$ ) lasted for two hours (4 to $6 \mathrm{pm}$ ), which coincides with the time of peak demand in California.

We are unsure the reasons behind the low spike on December 9 (Wednesday). Prices were higher than average that day, and in the hours 6 to 8 am and 9 to 10 am the price went above $\$ 100 /$ MWh. These are not traditionally high usage periods. One guess is that it was some sort of supply-side problem or market condition since those hours are not generally associated with high loads. Note that at certain periods, the LMPs are negative. Negative prices can be caused by over-generation, which could be the result of increased wind generation (CAISO 2007).

\subsubsection{Relative Mapping Methods}

To deal with electricity price volatility including long-term changes in energy costs, relative mappings of dynamic prices to operational modes could be used. These mappings can be based 
on customer choices (e.g., how long a customer is able to be in a certain operation mode), an "electricity price reference" (e.g., average or high price), or a price index (i.e., a non-dimensional number or percentage) that is customizable by individual facilities.

One simple concept to map prices to operational modes, as illustrated in Figure 7, would be to have customer-specified daily number of hours for each of the operational modes and then, given DA RTP rates, develop an operation schedule for the entire day. A customer chooses to be in high mode for " $x$ hours" and in moderate mode for " $y$ minus $x$ hours" of the day. The transitional prices are determined by looking at the price duration curves. In Year 1, the transition price between normal/moderate modes would be $\mathrm{D}$ and the transition price between moderate/high modes would be C. Similarly for Year 2, the normal/moderate transition would be $\mathrm{B}$ and the moderate/high transition would be A. This mapping method solves the problem of customers being in high and/or moderate mode more of the time due to increased energy costs over time. Customers could also specify different numbers of hours to be in different modes for different seasons, different days of the week, etc. For example, in California, it may make sense to be in high mode less in the winter than in the summer because retail prices are generally higher in the summer than in the winter.

One problem with this method is that customers could end up with higher or lower electricity bills than desired, since the customer does not directly control the transitional prices. For example, if a facility strategy is to be in high mode daily for two hours, on a particularly hot summer day with high electricity prices for more than two hours, the facility will be operating at moderate or normal modes when prices are still high. If the same facility experiences a cool summer day, they will still go into high mode for two hours, even though prices are low. One solution to this problem is to screen the next day's prices and then decide how many hours to be in each mode based on those prices. For instance, a facility could compute the average next day price. If the average is above a certain threshold, the facility is willing to be in high mode for two hours and moderate mode for four hours. If the average is below the threshold, the facility is willing to be in high mode for one hour and moderate more for two hours.

This sort of strategy might be particularly appealing to certain facility types. One example is refrigerated warehouses that may only be able to participate in DR events for two hours per day, but have the flexibility to participate at any time throughout the day. Therefore, they would like to only participate during the highest priced hours to maximize their savings. Even if electricity prices were very high on a certain day, most refrigerated warehouses would not be able to participate for more than a fixed number of hours: ensuring the quality of their refrigerated food is far more important than the monetary savings that would result from responding to prices. 


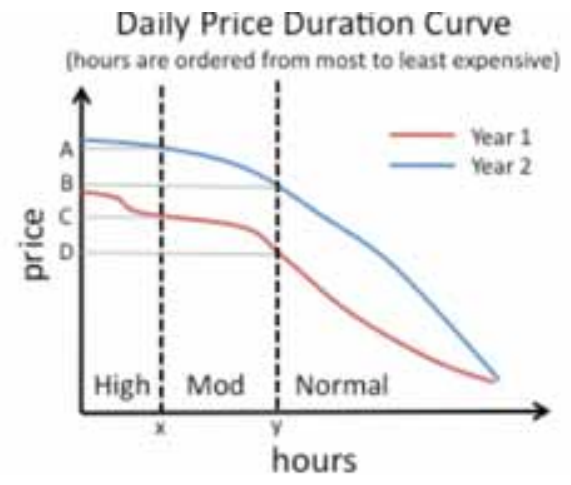

Figure 7. Relative Mapping with Number of Hours per Operation Mode

There are other methods that could use "electricity price reference" for next-day prices and map them to operational modes. As shown in Figure 8 below, two such potential methods use average and high electricity prices as a reference to calculate normal/moderate and moderate/high transition prices.

Using the Average Price Reference (left) one computes the average price over a next day and chooses the normal/moderate and moderate/high price transition as a percentage of the average price. For example, the normal/moderate transition could be 1.5x (150\%) of the average and the moderate/high transition could be $2 x(200 \%)$ of the average. Where high price is a concern, similarly, the High Price Reference (right) computes the high price over the next day and chooses the normal/moderate and moderate/high transition as a percentage of a high price. Price spikes pose problems with High Price Reference. For example, consider a facility that chooses to be in high mode if they are within $80 \%$ of the high price and in moderate mode if they are within $60 \%$ of the high price. On a particular day, if the electricity price spikes for just one hour it is possible that the facility will only be in high mode for that one hour, and the rest of the day they will be in normal mode because the prices during the rest of the day are less than $60 \%$ of the price spike. Potentially, the Minimum Price Reference could also be used; however, this method is also unreliable with significant drops in price. 
Daily Real-Time Prices

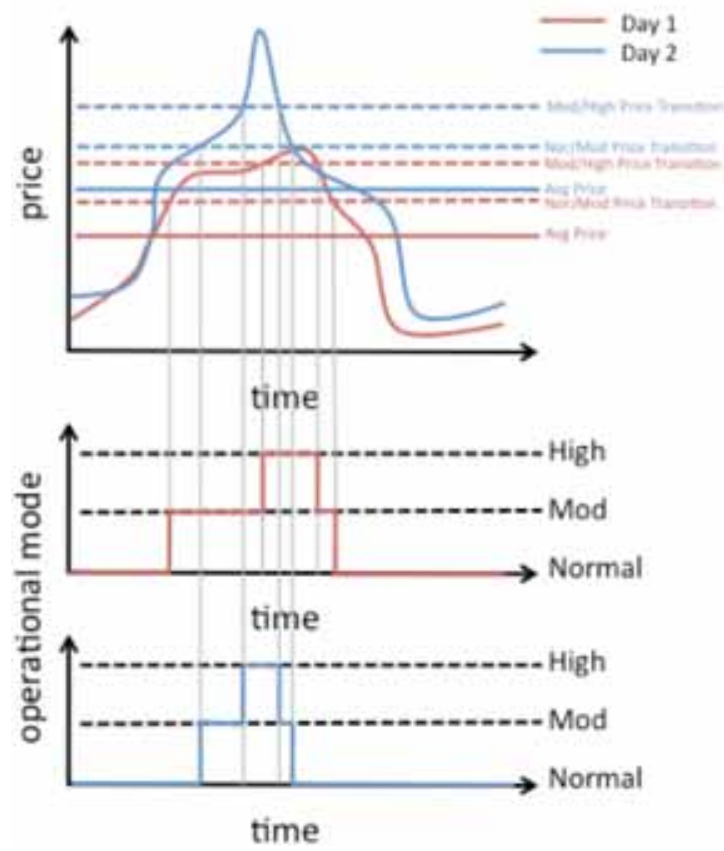

Daily Real-Time Prices

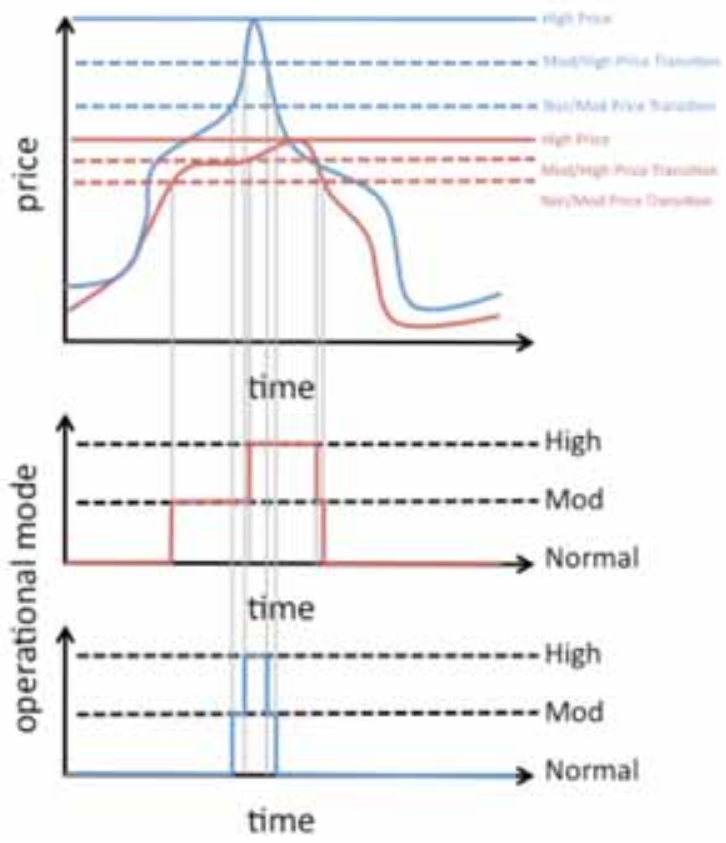

Figure 8. Relative Mapping Using Average (left) and High (right) Electricity Price References

\subsection{Summary}

Sending both simple and smart client information is very important when designing dynamic pricing models that are useful for both the current systems and future technology

advancements. Simple client information generated with absolute or relative mapping methods supplements smart client information. Facilities with simple control systems can use the simple client information, while facilities with the ability to process smart client information can use it directly.

Relative mapping methods are intended to moderate the amount of time that a facility is in high and/or moderate operation modes under normal price volatility conditions. They also require the facility to tune their choice of optimal percentages or optimal hours in each operational mode to get their desired response. The method of picking the number of high-price hours for a facility to participate is desirable for certain building types. Of the methods described that use the electricity price references, the Average Price Reference method is more robust than the High/Low Reference method. However, if retail price volatility is less significant than current wholesale price volatility (specifically if retail customers do not see spikes and drops), then relative mapping methods based on using low or high price references may work.

One alternative solution would be to create some sort of "Electricity Price Index" (i.e., a nondimensional number or percentage) based on historical prices and customer choices resulting from those prices or research of similar models used for financial markets. While this study explores the concept of Electricity Price Index for the first time, this research is still immature. 


\subsection{Conclusions and Future Directions}

\subsection{Conclusions}

This study has found that the OpenADR data models supports most day-ahead and day-of dynamic pricing structures for California utility retail electricity rates and independent system operator programs. The results from this technology demonstration are estimated to affect national retail dynamic pricing communication/policy. Related key findings are as follows:

- OpenADR data models can be used to send real-time prices.

- OpenADR RTP data models can also be used to support peak pricing and TOU rates.

- OpenADR customers can respond to dynamic prices by either using the actual prices or by mapping these prices into "operation modes" that can be used as inputs to control systems.

- Open ADR allows interoperability with existing and future systems and technologies.

- The results from this study could be used for wider application within Smart Grids.

\section{Key Challenges}

While there has been significant progress in demonstrating the application of OpenADR to a variety of dynamic pricing structures, there are a number of remaining key challenges such as the following:

- The OpenADR data model has placeholder for real-time feedback and energy use, which has had limited use in a few demonstrations. This information would be useful for facilities participating in programs such as peak-time rebate programs or those programs with demand charges.

- Wholesale energy market prices are volatile, and further research is needed on customer strategies to cope with the volatility of retail energy prices.

- Utilities use a variety of methods to set real-time prices (e.g., weather-dependent and market-dependent methods). More research is needed to determine the best ways for utilities to set real-time prices and how OpenADR can send them.

\section{Commercialization Potential}

This report discusses the representation of dynamic prices using OpenADR communication specifications Version 1.0 and related Auto-DR technologies to commercialized Auto-DR programs. With the national Smart Grid activities and OpenADR as a foundational standard for DR signals, the standardization of dynamic pricing signal communication could result in expansion of this technology to national markets. Significant commercialization opportunities exist in developing OpenADR clients to facilitate dynamic pricing response strategies and programs within existing and new markets. The evaluation of dynamic pricing for facilities may result in development of software to enable participation in dynamic pricing for cost, reliability, and societal benefits. 


\subsection{Future Directions}

OpenADR has been used in a variety of programs in California, the Northwest, and Canada, and it is in development for a number of other DR programs around the United States and abroad. OpenADR could benefit from the development and execution of future projects to demonstrate a broader set of capabilities. Future activities could include the following:

- Field demonstration of RTP data models and automated control response strategies in a variety of C\&I facilities.

- Assessment of the existing California default dynamic pricing programs' impact on facilities transitioning to Auto-DR.

- Further research on price-to-operational mode mapping strategies.

- Case studies on dynamic pricing programs in other areas (e.g., Georgia Power) and their applicability to OpenADR.

\subsection{Benefits to California}

The transition of California's electricity markets toward dynamic pricing (e.g., peak pricing) within the next few years could significantly impact electricity costs for many facilities. The price of electricity and the stress on the grid is high during peak days. Price response strategies allow customers to lower operational electricity costs and reduce grid stress. This results in alleviation of blackouts or brownouts and the need for peakier plants. Communicating prices can facilitate price response strategies. OpenADR-based infrastructure can communicate dynamic pricing information (e.g., hourly, sub-hourly) to facilities in real time while offering a secure and open system, enabling facilities to reduce their electricity costs. Standardized OpenADR interfaces can be used to link wholesale and retail real-time prices. 


\subsection{References}

Borenstein, S., M. Jaske, and A. Rosenfeld. 2002. “Dynamic Pricing, Advanced Metering and Demand Response in Electricity Markets." University of California Energy Institute: Center for the Study of Energy Markets Paper CSEMWP-105.

Borenstein, S. 2002. “The Trouble With Electricity Markets: Understanding California's Restructuring Disaster." J. Economic Perspectives 16: 191-211.

Bushnell, J., B. Hobbs, and F. Wolak. 2009. “When it Comes to Demand Response is FERC is own Worst Enemy?" The Electricity Journal 22(8): 9-18.

CAISO. 2007. “Integration of Renewable Resources: Transmission and Operating Issues and Recommendations for Integrating Renewable Resources on the California-ISO Controlled Grid." www.caiso.com/1ca5/1ca5a7a026270ex.html. Last accessed: 6/22/10.

CAISO. 2010. “OASIS - California ISO.” http://oasis.caiso.com/mrtu-oasis. Last accessed: $3 / 17 / 10$

Con Edison. 2010. "Demand Response/Day-Ahead Hourly Pricing Program." www.coned.com/energyefficiency/vol_time_pricing.asp. Last accessed: 3/17/10.

DOE. 2006. Benefits of Demand Response in Electricity Markets and Recommendations for Achieving Them. U.S. Department of Energy Report to the U.S. Congress www.oe.energy.gov/DocumentsandMedia/congress_1252d.pdf.

EPRI. 2009. Automated Demand Response Tests: An OpenADR Demonstration Project-Revision 1. EPRI. Palo Alto, California: 2009. Report No. 1018895.

FERC. 2009. A National Assessment of Demand Response Potential. Federal Energy Regulatory Commission Report. www.ferc.gov/legal/staff-reports/06-09-demand-response.pdf. Last accessed: 6/22/10.

FERC. 2010. National Action Plan on Demand Response. Federal Energy Regulatory Commission Report. www.ferc.gov/industries/electric/indus-act/demand-response/drpotential.asp. Last accessed: 6/19/10.

Granderson, J., M. A. Piette, G. Ghatikar, and P. Price. 2009. Building Energy Information Systems: State of Technology and User Case Studies. Lawrence Berkeley National Laboratory Report. LBNL-2899E.

Herter, K., and S. Wayland. 2008. Technology Evaluation of Programmable Communicating Thermostats with Radio Broadcast Data System Communications. California Energy Commission, PIER Energy Systems Integration Program.

Herter, K., S. Wayland, and J. Rasin. 2009. Small Business Demand Response with Communicating Thermostats: SMUD's Summer Solutions Research Pilot. Heschong Mahone Group for the California Energy Commission, PIER Building End-Use Energy Efficiency Program.

Herter, K., J. Rasin and T. Perry. 2010. Development and Demonstration of the Open Automated Demand Response Standard for the Residential Sector. California Energy Commission, PIER Buildings End-Use Energy Efficiency Program. CEC number forthcoming. 
ISO-NE. 2010. “ISO New England - Markets.” www.iso-ne.com/markets/. Last accessed: $3 / 17 / 10$.

Kiliccote S., M. A. Piette, G. Ghatikar, E. Koch, D. Hennage, J. Hernandez, A. Chiu, O. Sezgen, and J. Goodin. 2009. "Open Automated Demand Response Communications in Demand Response for Wholesale Ancillary Services." In Proceedings of Grid-Interop Forum 2009, Denver, Colorado. November 17-19, 2009. LBNL-2945E.

Kiliccote, S., M. A. Piette, and J. Dudley. 2010a. Northwest Open Automated Demand Response Demonstration Project. LBNL-2573E-Final.

Kiliccote, S., M. A. Piette, J. L. Mathieu, and K. M. Parrish. 2010b. Findings from Seven Years of Field Performance Data for Automated Demand Response in Commercial Buildings. In Proceedings of ACEEE Summer Study 2010, Pacific Grove, California. August 15-20, 2010. LBNL number forthcoming.

NERC. 2008. 2008 Long-Term Reliability Assessment: 2008-2017. North American Electric Reliability Corporation Report. www.nerc.com/files/LTRA2008.pdf. Last accessed: $6 / 22 / 10$.

NIST. 2010. NIST Framework and Roadmap for Smart Grid Interoperability Standards, Release 1.0. U.S. Department of Commerce and National Institute of Standards and Technology. www.nist.gov/public_affairs/releases/upload/smartgrid_interoperability_final.pdf. Last accessed: 6/22/10.

NYISO. 2010. "NYISO (Markets \& Operations - Market Data - Pricing Data)." www.nyiso.com/public/market_data/pricing_data.jsp. Last accessed: 3/17/10.

OASIS SDO. 2010a. “Energy Interoperability (Energy Interop) Technical Committee." Organization for Advancement of Structured Information Standards. www.oasisopen.org/committees/energyinterop/. Last accessed: 6/16/2010.

OASIS SDO. 2010b. "Energy Market Information Exchange (eMIX) Technical Committee." Organization for Advancement of Structured Information Standards. www.oasisopen.org/committees/emix/. Last accessed: 6/16/2010.

Open Smart Grid Users Group. “OpenADR Task Force.” 2010. Utilities Communications Architecture. http://osgug.ucaiug.org/sgsystems/OpenADR/. Last accessed: $6 / 16 / 2010$.

PG\&E. 2010a. "Electric Rate Schedules." www.pge.com/tariffs/. Last accessed: 4/26/10.

PG\&E. 2010b. "Peak Day Pricing." www.pge.com/mybusiness/energysavingsrebates/demandresponse/peakdaypricing/. Last accessed: 3/17/10.

Piette M. A, G. Ghatikar, S. Kiliccote, E. Koch, D. Hennage, P. Palensky, and C. McParland. 2009. "Open Automated Demand Response Communications Specification (Version 1.0)." California Energy Commission, PIER Program. CEC-500-2009-063. 
SCE. 2010a. "Critical Peak Pricing Rate Schedules." www.sce.com/NR/rdonlyres/B73F4175162B-4C4F-B953-4E0A94863390/0/08June_CPPFactSheet.pdf. Last accessed: 3/17/10.

SCE. 2010b. "RTP-2 General Service Real-Time Pricing." www.sce.com/NR/rdonlyres/6095C32C-C4B5-496F-B7C1AEF49B8E0C6C/0/NR598V20909_RTP2_Fact_Sheet.pdf. Last accessed: 3/17/10.

SDG\&E. 2010a. "Critical Peak Pricing." www.sdge.com/documents/business/savings/cpp/cpp_factsheet.pdf. Last accessed: $4 / 7 / 10$.

SDG\&E. 2010b. "Peak Time Rebate." www.sdge.com/tm2/pdf/ELEC_ELECSCHEDS PTR.pdf. Last accessed: 7/7/10.

Wikler, G., I. Bran, J. Prijyanonda, S. Yoshida, K. Smith, M. A. Piette, S. Kiliccote, G. Ghatikar, D. Hennage, and C. Thomas. 2007. “Auto-DR Assessment Study.” 2007 Auto-DR Program, Task 13 Deliverable. http://drrc.lbl.gov/pubs/pge-auto-dr-assessment-study.pdf. Last accessed 06/16/2010. 


\subsection{Glossary}

\begin{tabular}{|c|c|}
\hline API & Application Programming Interface \\
\hline Auto-DR & Automated Demand Response \\
\hline CAISO & California Independent System Operator \\
\hline C\&I & Commercial and Industrial \\
\hline CPP & Critical Peak Pricing \\
\hline CPUC & California Public Utilities Commission \\
\hline CSV & Comma-Separated Values \\
\hline $\mathrm{DA}$ & Day-Ahead \\
\hline DAM & Day-Ahead Market \\
\hline DBP & Demand Bidding Program \\
\hline $\mathrm{DO}$ & Day-of \\
\hline DOE & U.S. Department of Energy \\
\hline DR & Demand Response \\
\hline DRAS & Demand Response Automation Server \\
\hline DRRC & Demand Response Research Center \\
\hline EIS & Energy Information System \\
\hline EMCS & Energy Management Control System \\
\hline EPRI & Electric Power Research Institute \\
\hline FERC & Federal Energy Regulatory Commission \\
\hline FM & Frequency Modulation \\
\hline HASP & Hour-Ahead Scheduling Process \\
\hline ISO & Independent System Operator \\
\hline ISONE & Independent System Operator - New England \\
\hline LBNL & Lawrence Berkeley National Laboratory \\
\hline LMP & Locational Marginal Price \\
\hline MRTU & Market Redesign and Technology Upgrade \\
\hline NIST & National Institute of Standards and Technology \\
\hline NYISO & New York Independent Systems Operator \\
\hline OASIS & Open Access Same Time Information System \\
\hline OpenADR & Open Automated Demand Response \\
\hline PDP & Peak Day Pricing \\
\hline PG\&E & Pacific Gas and Electric Company \\
\hline PIER & Public Interest Energy Research \\
\hline RDS & Radio Data Systems \\
\hline RUC & Residual Unit Commitment \\
\hline SCE & Southern California Edison \\
\hline SDG\&E & San Diego Gas and Electric \\
\hline SMUD & Sacramento Municipal Utility District \\
\hline TOU & Time of Use \\
\hline XML & Extensible Mark-Up Language \\
\hline
\end{tabular}




\section{Appendix A: SCE RTP Tariff Structure}

This appendix, in reference to Section 2.0, describes and lists the tables for Southern California Edison's (SCE's) weather-based Real-Time Pricing (RTP) tariff structure for large (> $500 \mathrm{~kW})$ Commercial and Industrial (C\&I) facilities.

Table A.1 below shows the hourly RTP (24-hour) tariff conditions with start temperature as price triggers for different hours during the day.

Table A.1. SCE RTP Tariff Conditions for Weather (Temperature)

\begin{tabular}{|c|c|c|c|c|c|c|c|c|c|}
\hline MOUR ENDING & $\begin{array}{l}\text { EXTREMELY } \\
\text { MOT... }\end{array}$ & $\begin{array}{l}\text { VERY HOT } \\
\text { SUMMER } \\
\text { WEEKDAY }\end{array}$ & $\begin{array}{l}\text { HOT SUMMER } \\
\text { WEEKRAY }\end{array}$ & $\begin{array}{l}\text { MODERATE } \\
\text { SUMMER } \\
\text { WEEKDAY }\end{array}$ & $\begin{array}{l}\text { MTLO SUMMER } \\
\text { WEEKDAY }\end{array}$ & $\begin{array}{l}\text { HIGH COST } \\
\text { WINIER } \\
\text { WEEKDAY }\end{array}$ & $\begin{array}{l}\text { LOW COST } \\
\text { WINTER } \\
\text { WEEKDAY }\end{array}$ & $\begin{array}{l}\text { HIGH COST } \\
\text { WEEKEND }\end{array}$ & $\begin{array}{l}\text { LOW COST } \\
\text { WEEKEND }\end{array}$ \\
\hline Start Temporature & 95 & 91 & 85 & 81 & 0 & 90 & 0 & 78 & 0 \\
\hline $01: 00: 00$ & 0.05196 & 0.054 & 0.05261 & 0.05051 & 0.04038 & 0.04669 & 0.04116 & 0.05582 & 0.041 \\
\hline $02: 00: 00$ & 0.04487 & 0.04589 & 0.04439 & 0.04286 & 0.03308 & 0.04123 & 0.03703 & 0.04823 & 0.03304 \\
\hline $03: 00: 00$ & 0.0399 & 0.04086 & 0.04008 & 0.03896 & 0.03017 & 0.03922 & 0.03536 & 0.04419 & 0,02943 \\
\hline $04: 00: 00$ & 0.03836 & 0.03943 & 0.03876 & 0.03791 & 0.02937 & 0.03946 & 0.03624 & 0.04212 & 0.02784 \\
\hline $05: 00: 00$ & 0.04255 & 0.04332 & 0.0422 & 0.04133 & 0.03351 & 0.04543 & 0.04212 & 0.04369 & 0.02904 \\
\hline $06: 00=00$ & 0.05499 & 0.05425 & 0.05236 & 0.05215 & 0.04439 & 0.05907 & 0.05506 & 0.04729 & 0.0317 \\
\hline $07: 00: 00$ & 0.04934 & 0.04564 & 0.04482 & 0.04527 & 0.04109 & 0.06469 & 0.0621 & 0.0422 & 0.02441 \\
\hline Q8:00:00 & 0.06067 & 0.05733 & 0.05538 & 0.05435 & 0.05014 & 0.07022 & 0.06467 & 0.05045 & 0.03271 \\
\hline $09: 00: 00$ & 0.07866 & 0.08865 & 0.07127 & 0.06923 & 0.06185 & 0.08059 & 0.06945 & 0.06011 & 0.04132 \\
\hline 10:00:00 & 0.14628 & 0.13231 & 0.08351 & 0.08063 & 0.0721 & 0.11738 & 0.07353 & 0.06872 & 0.04836 \\
\hline$y z: 00: 00$ & 0.32053 & 0.272 & 0.1145 & 0.09283 & 0.08404 & 0.2004 & 0.07473 & 0.07551 & 0.05199 \\
\hline $12: 00: 00$ & 0,67595 & 0.41336 & 0.12752 & 0.0936 & 0.08423 & 0.25605 & 0.07621 & 0.07921 & 0.05437 \\
\hline 13:00:00 & 1.09312 & 0.5935 & 0.15871 & 0.10655 & 0.09012 & 0.36881 & 0.07721 & 0.08237 & 0.05591 \\
\hline $14: 00: 00$ & 1.89243 & 0.94612 & 0,33403 & 0.11567 & 0.0972 & 0.5632 & 0.07887 & 0.08509 & 0.05704 \\
\hline 15:00:00 & 2,71311 & 1. 20253 & 0.49561 & 0.1387 & 0.10153 & 0.70048 & 0.07881 & 0.08741 & 0.05769 \\
\hline $16: 00: 00$ & 3.74992 & 1.51581 & 0.60788 & 0.16428 & 0,10323 & 0.80914 & 0.07803 & 0.09021 & 0.05895 \\
\hline $57: 00: 00$ & 3.74171 & 1.38744 & 0.61672 & 0.15582 & 0.09957 & 0.67367 & 0.07811 & 0.09664 & 0.0624 \\
\hline $18: 00: 00$ & 2.81424 & 1.0862 & 0.42269 & 0.12896 & 0.09413 & 0.37445 & 0.0833 & 0.10352 & 0.06661 \\
\hline $19: 00: 00$ & 1.77045 & 0.56148 & 0.24536 & 0.11201 & 0.08718 & 0.28574 & 0.08333 & 0.10019 & 0.0669 \\
\hline $20: 00: 00$ & 1.25056 & 0.38472 & 0.18141 & 0.10855 & 0.08425 & 0.28497 & 0.08301 & 0.09686 & 0.06846 \\
\hline $21: 00: 00$ & 1.38676 & 0.61931 & 0.19252 & 0.09343 & 0.08855 & 0.33715 & 0.09591 & 0.09761 & 0.07469 \\
\hline $22: 00: 00$ & 0.28302 & 0.2441 & 0.09554 & 0.07664 & 0.07124 & 0.14889 & 0.0767 & 0.08292 & 0.06095 \\
\hline $23: 00: 00$ & 0.09659 & 0.12732 & 0.08952 & 0.08167 & 0.07889 & 0.09868 & 0.07393 & 0.08075 & 0.06646 \\
\hline $00: 00: 00$ & 0.06955 & 0.069 & 0.06556 & 0,0614 & 0.05751 & 0.06654 & 0.05719 & 0.06472 & 0.05091 \\
\hline
\end{tabular}

These hourly real-time prices vary based on seasons and holidays. Table A. 2 below shows the configurable tariff parameters by the utility operator. These configurable tariff parameters are used by SCE to configure summer and winter seasons (as prices vary by seasons) and any associated holidays (when prices do not apply).

Table A.2. SCE RTP Tariff Parameters for Seasonal (Summer/Winter) and Holidays

\begin{tabular}{|c|c|c|c|c|c|}
\hline & \multicolumn{2}{|c|}{ Start Dabe } & \multirow[b]{2}{*}{ Memorial Day } & \multicolumn{2}{|l|}{ Date: } \\
\hline SUMMER & $06 / 01 / 2010$ & 国 & & $05 / 31 / 2010$ & \#\# \\
\hline \multirow[t]{2}{*}{ WINTER } & $10 / 01 / 2010$ & 国 & Indeopendence Day & $07 / 04 / 2010$ & Ifi \\
\hline & & & Labor Day & $12 / 02 / 2012$ & 들 \\
\hline
\end{tabular}




\section{Appendix B: Screenshots of OpenADR Interfaces}

This appendix, in reference to Section 0, describes and lists the screen shots for the OpenADR system's graphical user interface (GUI), developed specifically for this study.

OpenADR v1.0 describes the data models and interfaces to communicate DR event information. The GUI implementations to represent these data models and interfaces are vendor-specific and their functionalities can vary. The screen shots for utility or ISO operator and participant dashboards, shown in this section, were specifically developed for demonstration of the OpenADR system in this study and can be used for future field-tests.

Figure B.1 below shows the screen shot of an interface that allows the utility or ISO operator to issue day-ahead (DA) or day-of (DO) real-time pricing (RTP) events to participants using manual entry and real-time Internet feeds. The "RTP DAM" and "RTP HASP" names denote the RTP using the California Independent System Operators' (CAISO) Open Access Same Time Information System (OASIS) real-time Internet feeds for Day-Ahead Market (DAM) and Day-Of (DO) Hour-Ahead Scheduling Process (HASP). The "DEMO" name denotes the RTP event entered manually. The utility or ISO operator GUI allows viewing the names of participants enrolled in a specific RTP program and editing the program parameters.

\begin{tabular}{|c|c|c|c|c|}
\hline \multicolumn{5}{|c|}{ Programs } \\
\hline & name & & action & \\
\hline 口 & RTP DAM & 2 & Add fvent & View Participants \\
\hline$\square$ & RTP HASP & $g$ & Add Event & View Participants \\
\hline ㅁ & DEMO & $y$ & Add Event & View Participants \\
\hline
\end{tabular}

Figure B.1. Utility or ISO Operator Dashboard: RTP Events Issued Using Manual and Internet Feeds

Figure B.2 below shows the screen shot of the manual interface that allows the utility or ISO operator to enter the prices directly for day-ahead (DA) or day-of (DO) dynamic prices. This example shows a customized hourly (60 minute) RTP event scheduled at 2 pm (14:00) the previous day for a four-hour event from 2 pm (14:00) to 6 pm (18:00) the next day. The other configurable parameters include time interval for prices (e.g., 15-min, 30-min, etc.), operation mode values (e.g., Normal, Moderate, High), and actual prices (e.g., \$0.10, \$1.00, etc.) that correspond to different hours. 


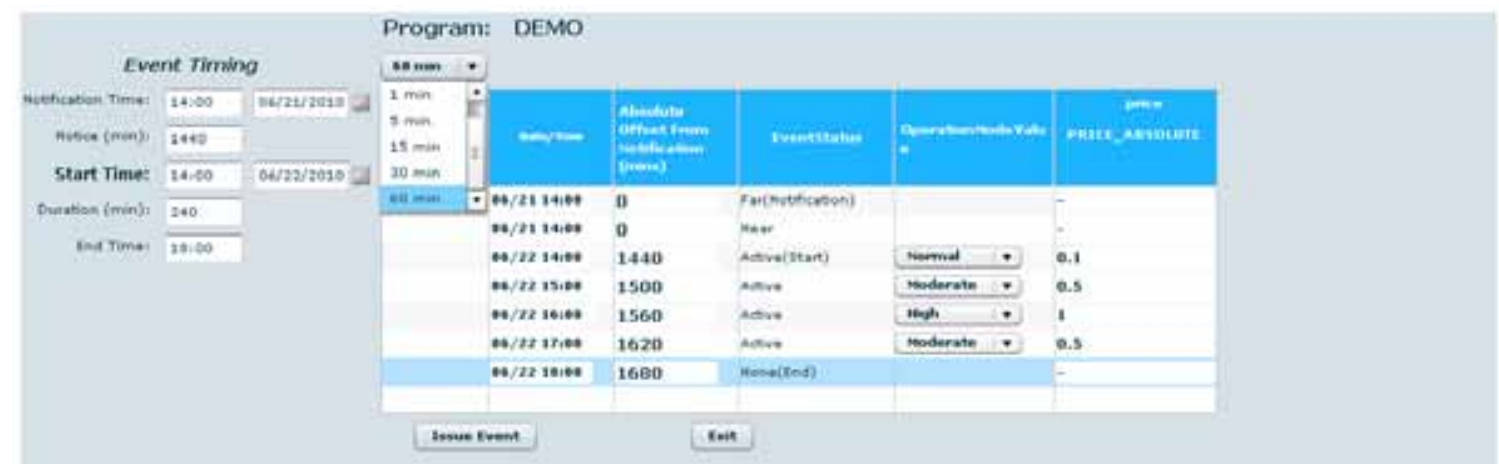

Figure B.2. Utility or ISO Operator Dashboard: Issue Manual DA and DO RTP Events

The Figures B.3 and B.4 below show the facility's participant dashboard for an OpenADR system. ${ }^{6}$ In the example GUI shown in Figure B.3 below, a facility's OpenADR client, "test.c1," is participating and has events "active" and "near" for CAISO's DAM and HASP, and manual DEMO RTP programs for the specified start and end time. This participant dashboard also shows other details related to the OpenADR client (e.g., client type, event status, communication).

\section{DRAS Participant Dashboard

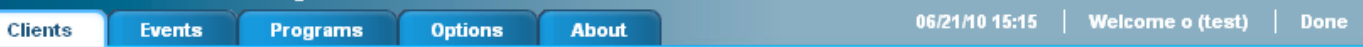

\begin{tabular}{|c|c|c|c|c|c|}
\hline Client & Type & Pending & Mode & Last Contact & Comm Status \\
\hline test.c1 & SOFTWARE & ACTIVE (ON) & $\mathrm{HIGH}$ & & OFFLINE \\
\hline
\end{tabular}

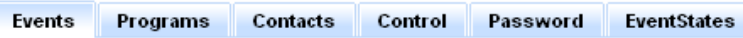

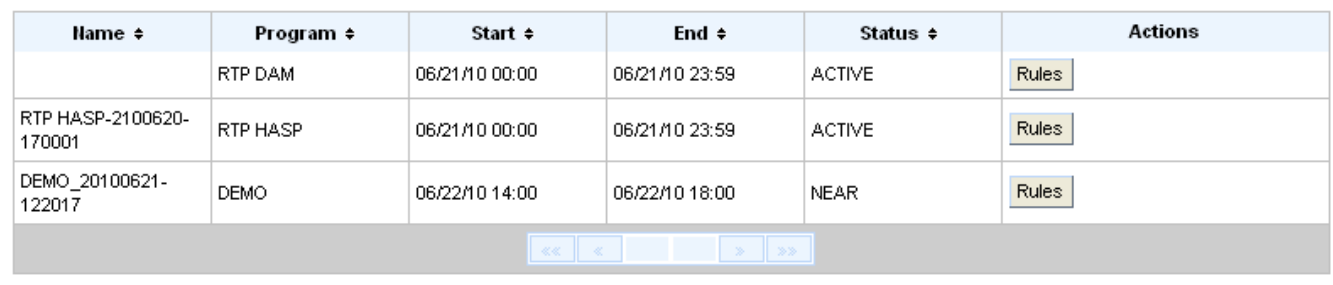 \\ Done}

Figure B.3. Participant Dashboard: RTP DR Event(s) Issued by Utility or ISO Operator

${ }^{6}$ This study uses OpenADR system to specify the OpenADR signaling system, which was formerly called as DRAS (Demand Response Automation Server) as shown in the figure. 
In the example shown in Figure B.4 below, for the same OpenADR client (test.c1), the GUI shows the time and signal types for both price $(\$ 0.10, \$ 1.00$, etc.) and its associated operation mode values (e.g., Normal, Moderate, and High) for a manually issued RTP event (see previous GUI). The rules for operation mode values are configurable and customizable by the facility.

\begin{tabular}{|c|c|c|c|c|}
\hline \multicolumn{4}{|c|}{$\begin{array}{l}\text { Signal Entries } \\
\text { Program: DEMO, Event: DEMO_20100621-122017, Comm Dev: test.c1 }\end{array}$} & \multirow[t]{2}{*}{+} \\
\hline & Time & Signal & Value & \\
\hline$\square$ & $06 / 22 / 10 \quad 14: 00: 00$ & price & 0.1 & \\
\hline$\square$ & $06 / 22 / 1016: 00: 00$ & price & 1.0 & \\
\hline$\square$ & $06 / 21 / 10$ 14:01:00 & pending & on & \\
\hline$\square$ & $06 / 22 / 10$ 14:00:00 & mode & normal & \\
\hline$\square$ & $06 / 22 / 10 \quad 16: 00: 00$ & mode & high & \\
\hline$\square$ & $06 / 22 / 10$ 17:00:00 & mode & moderate & \\
\hline
\end{tabular}

Figure B.4. Participant Dashboard: Manual RTP DR Event Signal Elements and Prices

Figures B.5 and B.6 below show the participant dashboard used to set the mapping strategies of an OpenADR client. In the example shown in Figure B.5 below, the facility specifies the mapping of smart client information (e.g., hourly prices) into simple client information (e.g., operation modes) for a specified start and end time of an RTP program. The operators (e.g., $<,>$, etc.) are used to create rules, and they define the price mapping to operation modes (e.g., Normal if price is $\leq \$ 0.50$ ). These operation modes are sent to the OpenADR client when the RTP event is issued.

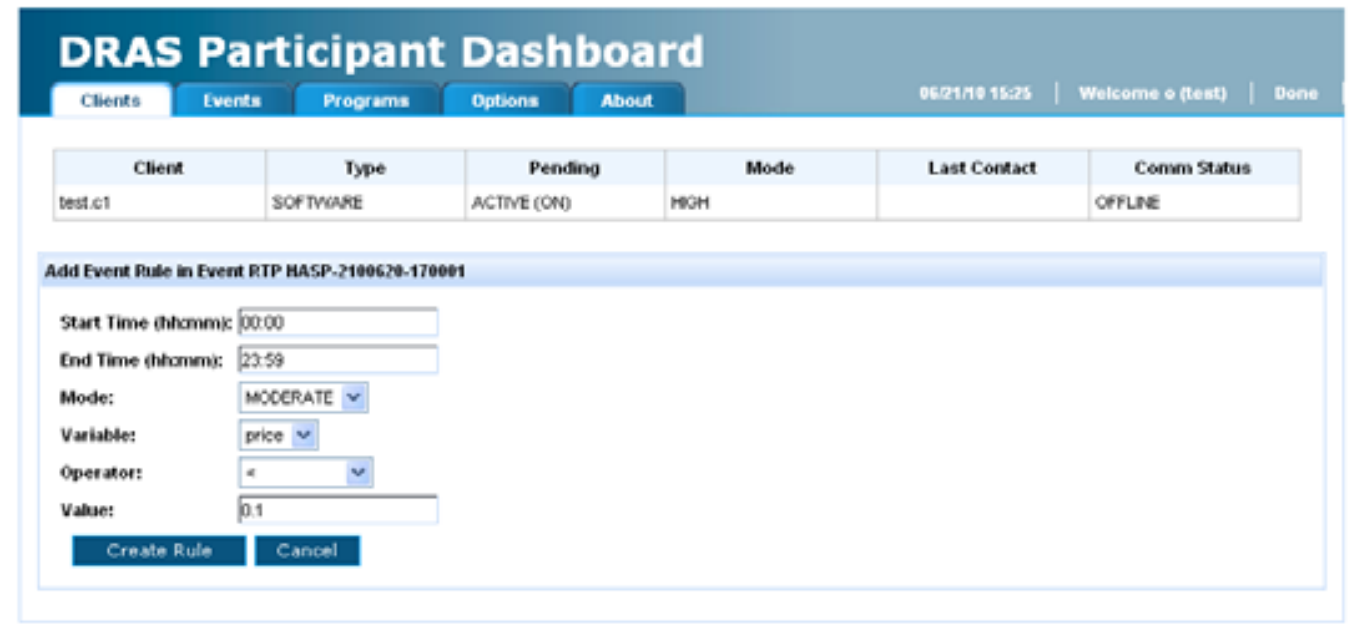

Figure B.5. Participant Dashboard: OpenADR Client Rules for Mapping Strategies

Figure B.6 below displays the entire OpenADR client mapping strategies of price values into operation modes for a specified start and end time of an RTP program. The OpenADR client receives these operation modes when the RTP event is issued for that program. 


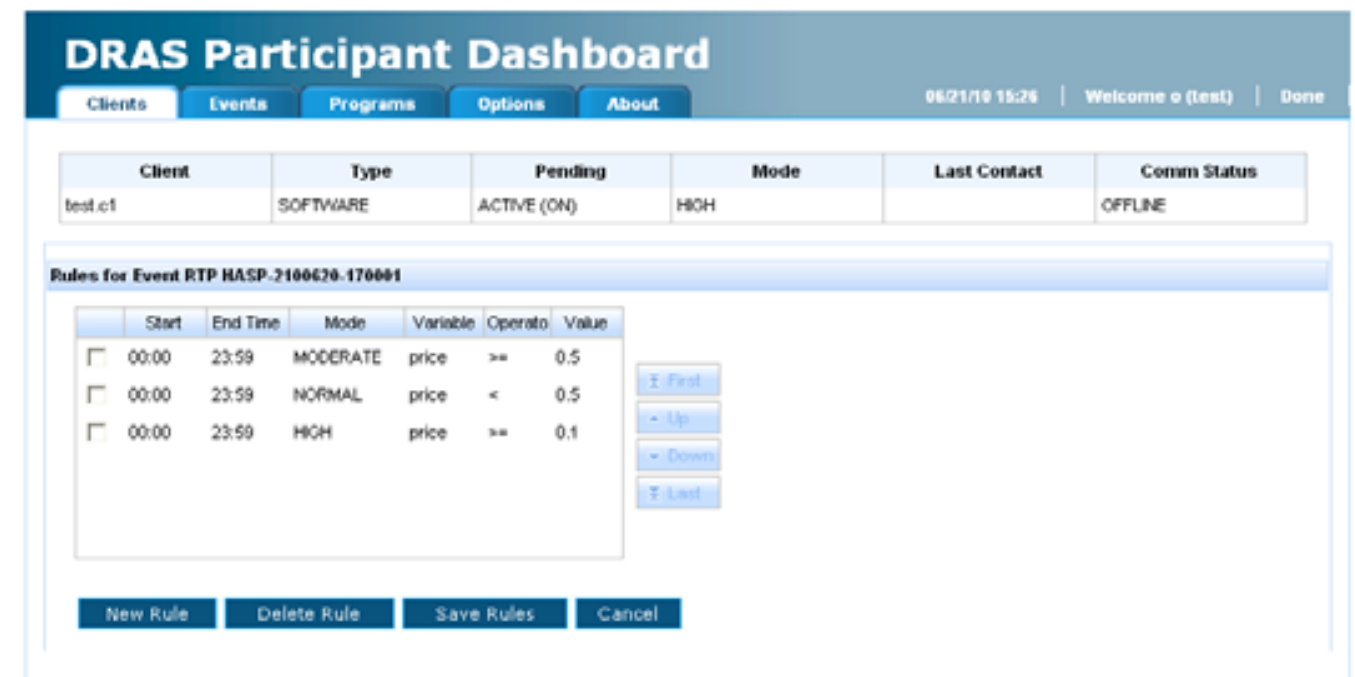

Figure B.6. Participant Dashboard: Mapping Strategies as Specified by a Facility

Other different operators (e.g., ALWAYS, =, NOT EQUAL) and mapping algorithms could be used to customize specific rules for a client. 


\section{Appendix C: CAISO Wholesale Prices and OASIS Data Models}

This appendix, in reference to Section 0, shows details of the California Independent System Operator (CAISO) wholesale real-time market prices and data models as described by the Open Access Same Time Information System (OASIS). These data models were used for integration with OpenADR data models and attributes to send real-time prices to retail customers.

Table C.1 below shows Hour-Ahead Scheduling Process (HASP) Interval Locational Marginal Prices (LMPs) retrieved from CAISO OASIS for hour ending 18 (6 pm) on February 11, 2010. The LMPs for four intervals (in \$/MWh for a 15-minute duration for this specific pricing program) are broken into three categories: congestion, energy, and losses. While more price details are relevant to wholesale customers, for retail customers the total LMP is most relevant and used by the OpenADR system.

Table C.1. CAISO OASIS HASP Interval Locational Marginal Prices. ${ }^{7}$

\begin{tabular}{|l|c|c|c|c|}
\hline HASP & INTERVAL01 & INTERVAL02 & INTERVAL03 & INTERVAL04 \\
\hline $02 / 11 / 2010-$ Hour Ending 18 & \multicolumn{4}{|l|}{} \\
\hline 3EMIIIO6 N001 & \multicolumn{4}{|l|}{} \\
\hline LMP & 37.33727 & 40.67788 & 47.29002 & 68.27046 \\
\hline Congestion & 0.00000 & 0.00000 & 0.00000 & 0.00000 \\
\hline Energy & 38.29071 & 41.74231 & 48.55238 & 70.05691 \\
\hline Loss & -0.95344 & -1.06443 & -1.26236 & -1.78645 \\
\hline
\end{tabular}

The CAISO publishes these LMPs using eXtensible Mark-up Language (XML) data models for all of its wholesale real-time market pricing programs. The sections below show two representative XML data models that were used for OpenADR technology demonstration. ${ }^{8}$

\section{CAISO OASIS LMP Data Model for Day-Ahead Real-Time Market Prices}

The following is the XML data model (schema) for LMPs published by CAISO OASIS for DA wholesale real-time markets for each of the nodes. While all the details of these data models may not be relevant, it would be interesting to note the bold text in the schema. The data models show issuing entity, program/market type, unit of measurement (UOM), interval (3600 seconds for one-hour) ,resource (node) name, date, time interval (1 signifies $12 \mathrm{am}$ ), and price values, including each of the categories (congestion, energy, and losses) for twenty-four hours.

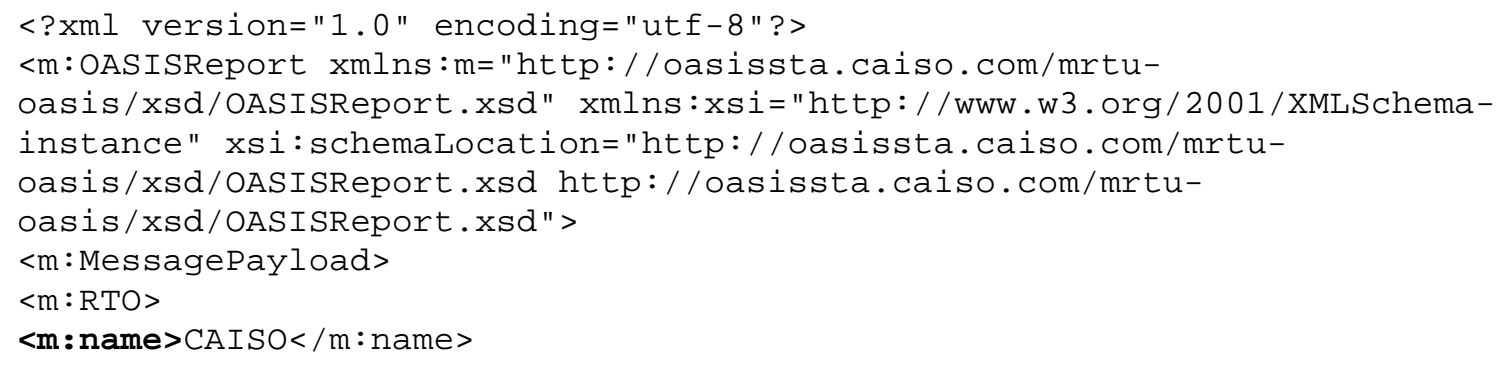

\footnotetext{
${ }^{7}$ These tables were generated from data obtained through OASIS on 02/11/2010, hour ending 6 pm (18).

${ }^{8}$ The XML data models were generated and abbreviated from data obtained through OASIS on 02/11/2010 and 02/12/2010 for same node with identification “3EMIDIO_6_N001."
} 


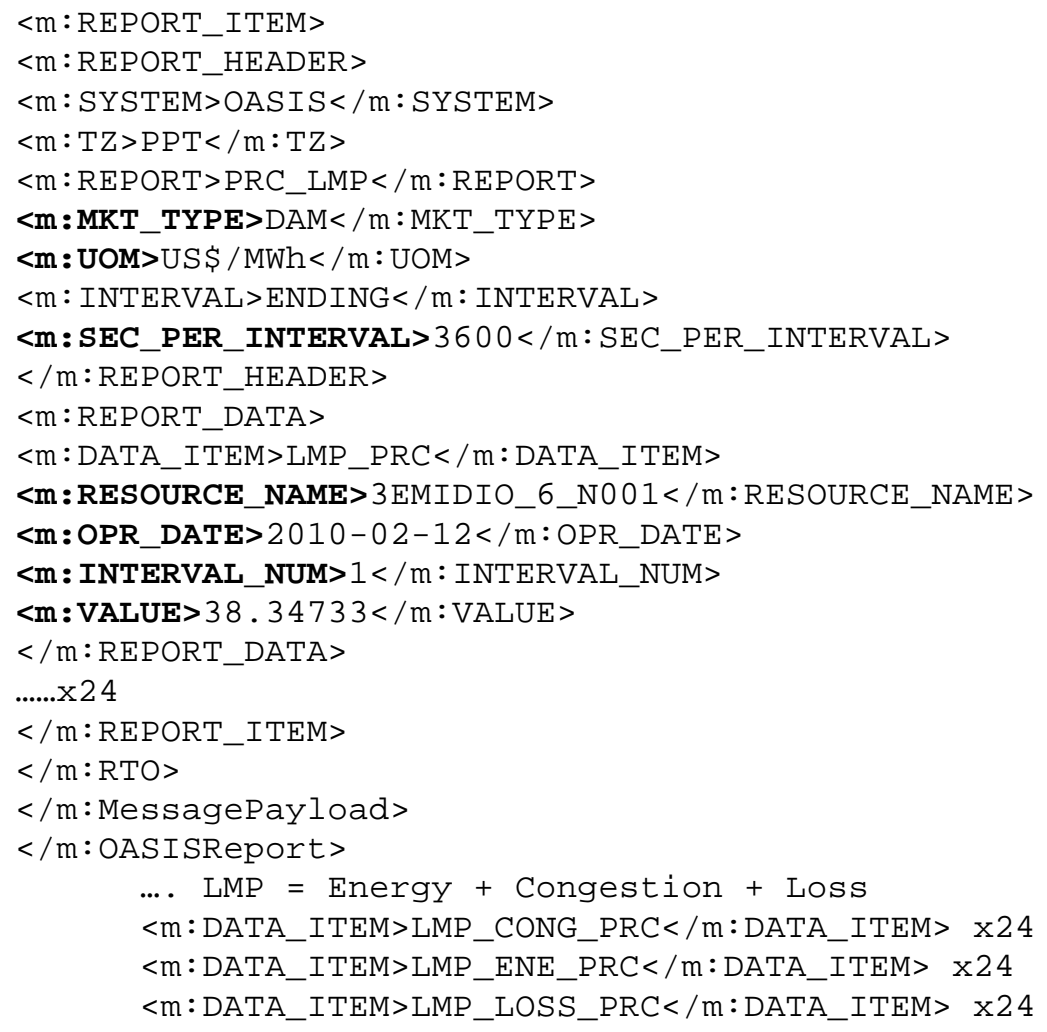

\section{CAISO OASIS HASP LMP Data Model for Day-of Real-Time Market Prices}

The following is the XML data model (schema) for HASP LMP published by CAISO OASIS for DO wholesale real-time markets for each of the nodes. While all the details of these data models may not be relevant, it would be interesting to note the bold text in the schema. The data models show issuing entity, program/market type, unit of measurement (UOM), interval (900 seconds for 15-minutes) resource (node) name, date, time interval (56 signifies 2 pm because the count starts at 1, which signifies 12 am and each hour thereafter is broken into four numbers of 15-minute duration each), and price values, including each of the categories (congestion, energy, and losses) for twenty-four hours.

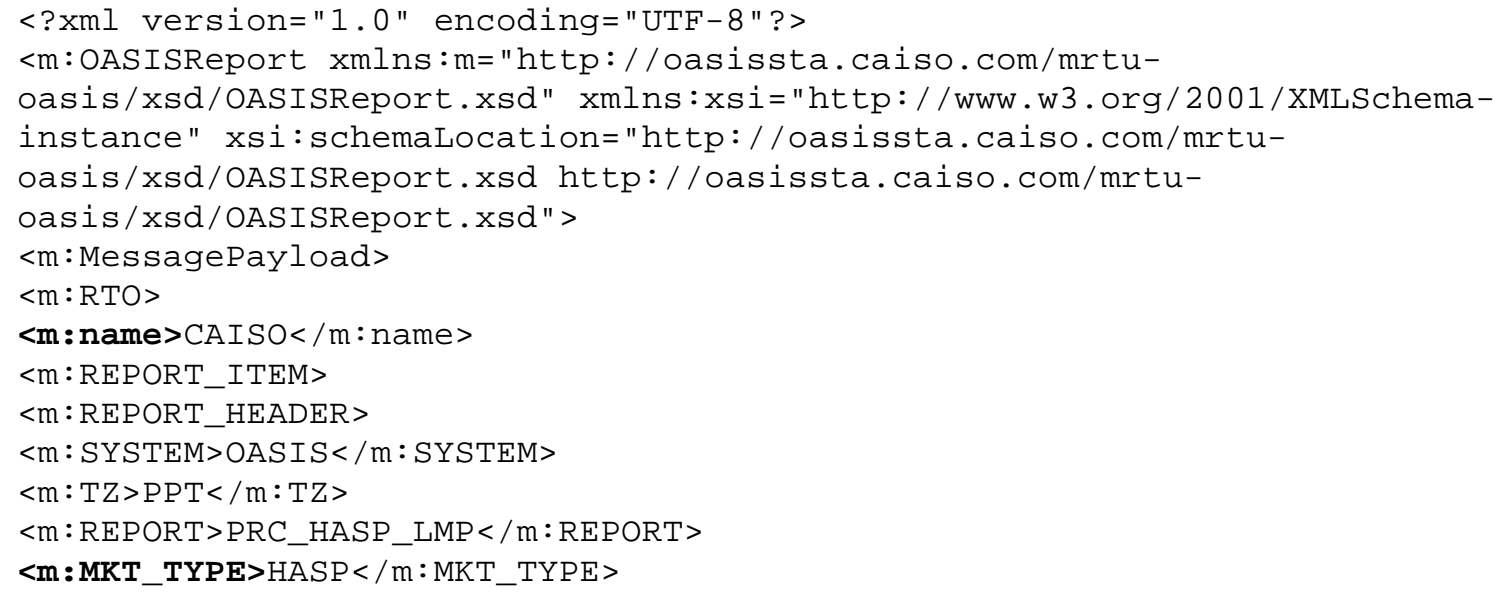


$<\mathrm{m}: \mathrm{UOM}>\mathrm{US} \$ / \mathrm{MWh}</ \mathrm{m}: \mathrm{UOM}>$

$<\mathrm{m}:$ INTERVAL $>$ BEGINNING $</ \mathrm{m}$ : INTERVAL $>$

$<\mathrm{m}:$ SEC_PER_INTERVAL $>900</ \mathrm{m}:$ SEC_PER_INTERVAL $>$

$</$ m :REPORT_HEADER $>$

$<\mathrm{m}:$ REPORT_DATA $>$

$<\mathrm{m}:$ DATA_ITEM $>$ LMP_CONG_PRC $</ \mathrm{m}$ :DATA_ITEM $>$

$<\mathrm{m}:$ RESOURCE_NAME $>3 E M I D I O \_6 \_N 001</ \mathrm{m}:$ RESOURCE_NAME $>$

$<$ : OPR_DATE $>2010-02-11</ \mathrm{m}$ : OPR_DATE $>$

$<$ m: INTERVAL_NUM> 56 </m:INTERVAL_NUM> -- (COUNT OF 96 intervals)

$<$ m:VALUE $>38.34733</ m$ : VALUE $>$

$</ \mathrm{m}$ :REPORT_DATA $>$

APC-3 


\section{Appendix D: PG\&E PDP Rate Schedules and Rate Sheets}

This appendix, in reference to Section 0, describes PG\&E's PDP rate schedules E-20, E-19, A-6, and $\mathrm{A}-1$ and lists actual rate information from the rate sheets used for our peak pricing and TOU analysis: ${ }^{9}$

1. PDP Rate Schedule E-20: “A customer is eligible for service under Schedule E-20 if the customer's maximum demand has exceeded 999 kilowatts for at least three consecutive months during the most recent 12-month period."10

2. PDP Rate Schedule E-19: “A customer must take service under Schedule E-19 if: (1) the customer's load does not meet the Schedule E-20 requirements, but (2) the customer's maximum billing demand has exceeded 499 kilowatts for at least three consecutive months during the most recent 12-month period."11

3. PDP Rate Schedule A-6: "This time-of-use schedule applies to single-phase and Polyphase alternating-current service. This schedule is not available to residential or agricultural service for which a residential or agricultural schedule is applicable, except for single-phase and Polyphase service in common areas in a multifamily complex." ${ }^{\prime 2}$

4. PDP Rate Schedule A-1: “Applies to single-phase and Polyphase alternating-current service. This schedule is not available to residential or agricultural service for which a residential or agricultural schedule is applicable, except for single-phase and Polyphase service in common areas in a multifamily complex. This schedule is also not available to customers whose meter indicates a maximum demand of $200 \mathrm{~kW}$ or greater for three consecutive months, except customers that are identified as load research sites."13

Starting May 1, 2010, the high-demand customers with ( $\geq 200 \mathrm{~kW}$ ) on E-19, E-20, A-10 (and other) rate schedules are eligible for automation using OpenADR.

The Tables D.1 to D.4 below show the snapshot of the peak day pricing electric rate schedules and related information considered for this study. These snapshots were taken from the same sources used to describe the PG\&E peak day pricing rate schedules above.

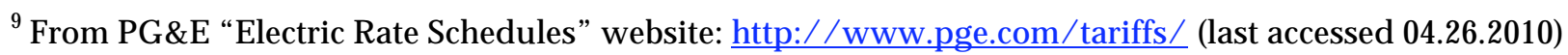

${ }^{10}$ Source: http://www.pge.com/tariffs/tm2/pdf/ELEC SCHEDS E-20.pdf (last accessed 04.26.2010)

${ }^{11}$ Source: http://www.pge.com/tariffs/tm2/pdf/ELEC_SCHEDS_E-19.pdf (last accessed 04.26.2010)

${ }^{12}$ Source: http://www.pge.com/tariffs/tm2/pdf/ELEC SCHEDS A-6.pdf (last accessed 04.26.2010)

${ }^{13}$ Source: http://www.pge.com/tariffs/tm2/pdf/ELEC_SCHEDS_A-1.pdf (last accessed 04.26.2010)
} 
Table D.1. Snapshot of PG\&E's PDP E-20 Rate Schedule

ELECTRIC SCHEDULE E-20

Sheet 3

\section{SERVICE TO CUSTOMERS WITH MAXIMUM DEMANDS of 1000 KILOWATTS or MORE}

3. RATES: Total bundled service charges are calculated using the total rates shown below. Direct Access (DA) and Community Choice Aggregation (CCA) charges shall be calculated in accordance with the paragraph in this rate schedule titled Billing.

\begin{tabular}{|c|c|c|c|c|c|c|}
\hline Iotal Customeralater Charge Rates & \multicolumn{2}{|c|}{$\begin{array}{l}\text { Secondary } \\
\text { Voltage }\end{array}$} & \multicolumn{2}{|l|}{$\begin{array}{l}\text { Primary } \\
\text { Voltage }\end{array}$} & \multicolumn{2}{|c|}{$\begin{array}{l}\text { Transmission } \\
\text { Voltage }\end{array}$} \\
\hline $\begin{array}{l}\text { Customer Charge Mandatory E-20 } \\
\text { (s per meter per day) }\end{array}$ & \multicolumn{2}{|c|}{$\$ 24.64066$} & \multicolumn{2}{|l|}{$\$ 32.85421$} & \multicolumn{2}{|c|}{$\$ 36.99220$} \\
\hline $\begin{array}{l}\text { Optional Meter Data Access Charge } \\
\text { ( } \$ \text { per meter per day) }\end{array}$ & \multicolumn{2}{|l|}{$\$ 0.98563$} & \multicolumn{2}{|l|}{ \$0.98563 } & \multicolumn{2}{|l|}{ \$o. 98563} \\
\hline \multicolumn{7}{|l|}{ Total Demand Rates (S per kW) } \\
\hline Maximum Peak Demand Summer & $\$ 12.78$ & & $\$ 12.10$ & & $\$ 11.12$ & \\
\hline Maximum Part-Peak Demand Summer & $\$ 2.84$ & & $\$ 280$ & & $\$ 2.49$ & \\
\hline Maximum Demand Summer & $\$ 9.00$ & (I) & $\$ 7.52$ & (1) & $\$ 4.28$ & (I) \\
\hline Maximum Part-Peak Demand Winter & $\$ 1.15$ & & $\$ 0.74$ & & $\$ 0.00$ & \\
\hline Maximum Demand Winter & $\$ 9,00$ & (1) & $\$ 7.52$ & (1) & $\$ 4.28$ & (i) \\
\hline \multicolumn{7}{|l|}{ Iotal Energy Rates ( $\mathrm{S}$ per $\mathrm{kWh}$ ) } \\
\hline Peak Summer & $\$ 0.14889$ & (1) & $\$ 0.15228$ & (1) & $\$ 0.10822$ & (1) \\
\hline Part-Peak Summer & $\$ 0.10429$ & (i) & \$0. 10453 & (i) & $\$ 0.08774$ & (i) \\
\hline Ont-Peak Summer & 50,08593 & (1) & S0.08391 & (i) & $\$ 0.07552$ & (i) \\
\hline Part-Peak Winter & $\$ 0.09372$ & (i) & \$0.09048 & (i) & $\$ 0.08032$ & (i) \\
\hline Oft-Peak Winter & $\$ 0.08322$ & (1) & $\$ 0.08004$ & (i) & $\$ 0.07189$ & (i) \\
\hline $\begin{array}{l}\text { Average Rate Limiter ( } \$ / \mathrm{kWh} \text { in summer } \\
\text { months) }\end{array}$ & $\$ 0.24001$ & (1) & 5024001 & (1) & - & \\
\hline Power Factor Adjustment Rate $(\$ / k W h / \%)$ & $\$ 0.00005$ & & $\$ 0,00005$ & & \$0.00005 & \\
\hline
\end{tabular}

Table D.2. Snapshot of PG\&E's PDP E-19 Rate Schedule

TOTAL RATES

Total CustomeriMeter Charge Rates

Customer Charge Mandatory E-19 (\$ per meter per day)

Customer Charge Voluntary E-19.

Customer Charge with SmartMeter ${ }^{\text {th }}$ (\$ per meter per day)

Customer Charge Rate V (\$ per meter per day)

Customer Charge Rate W (\$ per meter per day)

Customer Charge Rate X (\$ per meter per day)

Optional Meter Data Access Charge (\$ per meter per day)

Total Demand Rates (s per kW)

Maximum Peak Demand Summer

Maximum Part-Peak Demand Summer

Maximum Demand Summer

Maximum Part-Peak Demand Winter

Maximum Demand Winter

Total Energy Rates (\$ per kWh)

Peak Summer

Part-Peak Summer

Off-Peak Summer

Part-Peak Winter

Off-Peak Winter

Average Rate Limiter ( $\$ / \mathrm{kWh}$ in summer months)

Power Factor Adjustment Rate $(\$ / \mathrm{kWh} / \%)$

\begin{tabular}{|c|c|c|c|c|}
\hline \multicolumn{2}{|l|}{$\begin{array}{l}\text { Secondary } \\
\text { Voltage }\end{array}$} & \multicolumn{2}{|l|}{$\begin{array}{l}\text { Primary } \\
\text { Voltage }\end{array}$} & $\begin{array}{c}\text { Transmission } \\
\text { Voltage }\end{array}$ \\
\hline$\$ 13.55236$ & & $\$ 19.71253$ & & $\$ 39.42505$ \\
\hline$\$ 3.94251$ & & $\$ 3.94251$ & & $\$ 3.94251$ \\
\hline \$4.11992 & & $\$ 4.11992$ & & $\$ 4.11992$ \\
\hline$\$ 3.97799$ & & $\$ 3.97799$ & & $\$ 3.97799$ \\
\hline$\$ 4.11992$ & & $\$ 4.11992$ & & $\$ 4.11992$ \\
\hline$\$ 0.98563$ & & $\$ 0.98563$ & & $\$ 0.98563$ \\
\hline$\$ 13.17$ & & $\$ 11.89$ & & $\$ 9.16$ \\
\hline$\$ 3.02$ & & $\$ 2.72$ & & $\$ 2.07$ \\
\hline$\$ 9.02$ & (I) & $\$ 7.88$ & (I) & $\$ 5.80$ \\
\hline$\$ 1.15$ & & $\$ 0.87$ & & $\$ 0.00$ \\
\hline$\$ 9.02$ & (1) & 57.88 & (1) & $\$ 5.80$ \\
\hline$\$ 0.15568$ & (i) & $\$ 0.15520$ & (i) & $\$ 0,11577$ (1) \\
\hline$\$ 0.10813$ & (i) & $\$ 0.10603$ & (i) & $\$ 0.09372$ (1) \\
\hline$\$ 0.08871$ & (i) & \$0.08482 & (i) & 50.08054 (I) \\
\hline$\$ 0.09682$ & (1) & $\$ 0.09180$ & (1) & $\$ 0.08572(1)$ \\
\hline$\$ 0.08585$ & (i) & $\$ 0.08101$ & (i) & $\$ 0.07662$ (1) \\
\hline 50.24746 & (1) & 50.24746 & (1) & - \\
\hline$\$ 0.00005$ & & $\$ 0.00005$ & & $\$ 0.00005$ \\
\hline
\end{tabular}


Table D.3. Snapshot of PG\&E's PDP A-6 Rate Schedule

ELECTRIC SCHEDULE A-6

Sheet 3

\section{SMALL GENERAL TIME-OF-USE SERVICE}

TERRITORY: This rate schedule applies everywhere PG\&E provides electric service.

RATES: Total bundled service charges are calculated using the total rates shown below. Direct Access (DA) and Community Choice Aggregation (CCA) charges shall be calculated in accordance with the paragraph in this rate schedule titled Billing.

TOTAL RATES

Total Customer/Meter Charge Rates

Customer Charge Single-phase (\$ per meter per day) \$0.29569

Customer Charge Poly-phase (\$ per meter per day) \$ \$0.44353

Meter Charge (A-6) (\$ per meter per day) $\quad \$ 0.20107$

Meter Charge (W) (\$ per meter per day) \$0.05914

Meter Charge (X) (\$ per meter per day) $\quad \$ 0.20107$

Total Energy Rates (\$ per kWh)

Peak Summer $\$ 0.41487 \quad$ (I)

Part-Peak Summer $\$ 0.18872$ (I)

Off-Peak Summer $\$ 0.11732 \quad$ (I)

Part-Peak Winter $\quad \$ 0.14196$ (I)

Off-Peak Winter $\$ 0.11603$ (I)

Table D.4. Snapshot of PG\&E's PDP A-1 Rate Schedule

ELECTRIC SCHEDULE A-1

RATES: Total bundled service charges shown on customers' bills are unbundled according to the
(Cont'd.)
component rates shown below.

UNBUNDLING OF TOTAL RATES

Customer Charge Rates: Customer charge rates provided in the Total Rate section above are assigned entirely to the unbundled distribution component.

Energy Rates by Components ( $\$$ per kWh)

\begin{tabular}{lcc}
\hline Generation: & & \\
Summer & $\$ 0.11246$ & (1) \\
Winter & $\$ 0.06942$ & (I) \\
Distribution** & & \\
Summer & $\$ 0.05727$ \\
Winter & $\$ 0.03819$ \\
& & \\
Transmission* (all usage) & $\$ 0.01041$ & (I) \\
Transmission Rate Adjustments* (all usage) & $(\$ 0.00137)$ & (I) \\
Reliability Services* (all usage) & $\$ 0.00044$ \\
Public Purpose Programs (all usage) & $\$ 0.00607$ \\
Nuclear Decommissioning (all usage) & $\$ 0.00028$ \\
Competition Transition Charges (all usage) & $\$ 0.00736$ \\
Energy Cost Recovery Amount (all usage) & $\$ 0.00231$ \\
Fixed Transition Amount (all usage) & $\$ 0.00000$ \\
Rate Reduction Bond Memorandum Account** (all usage) & $(\$ 0.00034)$ \\
DWR Bond (all usage) & $\$ 0.00491$
\end{tabular}

